\title{
Adverse Drug Events and Medication Errors in African Hospitals: A Systematic Review
}

\author{
Alemayehu B. Mekonnen ${ }^{1,2}$ - Tariq M. Alhawassi ${ }^{3,4}$ • Andrew J. McLachlan ${ }^{1,5}$ • \\ Jo-anne E. Brien ${ }^{1,6}$
}

Published online: 14 November 2017

(c) The Author(s) 2017. This article is an open access publication

\begin{abstract}
Background Medication errors and adverse drug events are universal problems contributing to patient harm but the magnitude of these problems in Africa remains unclear.

Objective The objective of this study was to systematically investigate the literature on the extent of medication errors and adverse drug events, and the factors contributing to medication errors in African hospitals.

Methods We searched PubMed, MEDLINE, EMBASE, Web of Science and Global Health databases from inception to 31 August, 2017 and hand searched the reference lists of included studies. Original research studies of any
\end{abstract}

Electronic supplementary material The online version of this article (https://doi.org/10.1007/s40801-017-0125-6) contains supplementary material, which is available to authorized users.

Alemayehu B. Mekonnen

aber5592@uni.sydney.edu.au

1 Faculty of Pharmacy, University of Sydney, S114, Pharmacy Building A15, Sydney, NSW 2006, Australia

2 School of Pharmacy, University of Gondar, Gondar, Ethiopia

3 College of Pharmacy, King Saud University, Riyadh, Saudi Arabia

4 Medication Safety Research Chair, King Saud University, Riyadh, Saudi Arabia

5 Centre for Education and Research on Ageing, Concord Hospital, Sydney, NSW, Australia

6 Faculty of Medicine, St Vincent's Hospital Clinical School, University of New South Wales, Sydney, NSW, Australia design published in English that investigated adverse drug events and/or medication errors in any patient population in the hospital setting in Africa were included. Descriptive statistics including median and interquartile range were presented.

Results Fifty-one studies were included; of these, 33 focused on medication errors, 15 on adverse drug events, and three studies focused on medication errors and adverse drug events. These studies were conducted in nine (of the 54) African countries. In any patient population, the median (interquartile range) percentage of patients reported to have experienced any suspected adverse drug event at hospital admission was $8.4 \%$ (4.5-20.1\%), while adverse drug events causing admission were reported in $2.8 \%$ $(0.7-6.4 \%)$ of patients but it was reported that a median of $43.5 \%(20.0-47.0 \%)$ of the adverse drug events were deemed preventable. Similarly, the median mortality rate attributed to adverse drug events was reported to be $0.1 \%$ (interquartile range $0.0-0.3 \%$ ). The most commonly reported types of medication errors were prescribing errors, occurring in a median of $57.4 \%$ (interquartile range $22.8-72.8 \%$ ) of all prescriptions and a median of $15.5 \%$ (interquartile range $7.5-50.6 \%$ ) of the prescriptions evaluated had dosing problems. Major contributing factors for medication errors reported in these studies were individual practitioner factors (e.g. fatigue and inadequate knowledge/training) and environmental factors, such as workplace distraction and high workload.

Conclusion Medication errors in the African healthcare setting are relatively common, and the impact of adverse drug events is substantial but many are preventable. This review supports the design and implementation of preventative strategies targeting the most likely contributing factors. 


\section{Key Points}

This is the first literature review of African-based studies that focuses on medication errors and adverse drug events.

There have been limited reports on medication safety in African countries in the past, but this is rapidly increasing.

Of all patients admitted to hospital, a median of $2.8 \%$ of adverse drug events resulted in hospital admission in the general population, ranging to as high as 5.5\% in the adult population.

Regardless of the medication use process, dosing problems were the most commonly reported type of error.

\section{Introduction}

Quality patient care is a priority in all healthcare systems; however, patient safety can be compromised leading to potential medical harms [1]. Patient safety has been a growing priority led by pioneer US studies: the Harvard Medical Practice Study [2, 3] and the Institute of Medicine Report [4]. In USA, it has been reported that $3.7 \%$ of all hospitalised patients experienced an adverse event [2], and preventable adverse drug events (ADEs) alone resulted in 7000 deaths annually [4]. Despite developments in healthcare, these incidents continue to pose a significant problem globally $[5,6]$ and remain a concern for consumers, many practitioners and patient safety advocates.

Patient safety is a human rights issue and a subject matter increasingly researched in many developed countries [7]. However, in the absence of comprehensive healthcare coverage in the developing countries of Africa, assuring patient safety remains a considerable challenge when countries strive to provide quality patient care. According to the United Nations [8], Africa consists of 54 fully recognised member states with a current population of approximately 1 billion, and more than $40 \%$ of the population in the sub-Saharan Africa is in extreme poverty [9]. The average health expenditure per person in sub-Saharan Africa countries is below US $\$ 100$ per annum compared with US\$6110 in Australia and US\$9146 in USA [10]. Healthcare systems in Africa face severe health threats in the context of scarce resources and underdeveloped healthcare infrastructure, and the spectrum of patient safety problems in this continent is unique in that most countries lack integrated automated health systems to support patient care [11].

Patient injuries attributed to medication misadventures, including medication errors (MEs) and ADEs, are among the most common incidents in hospitals [2] and have important clinical, economic and social consequences. For example, a review of Australian [12] medication safety literature in 2003 showed that $2-4 \%$ of all hospital admissions are thought to be medication related. An updated review in 2009 [13] consistently reported a similar burden of medication-related morbidity costing the Australian healthcare system US\$660 million annually. However, given the distinct nature of the morbidity profile and drug utilisation pattern, and the level of awareness and patient safety culture, the burden of medication-related problems cannot be extrapolated for areas of poverty in Africa [11].

While there have been many previous reviews of the literature related to the burden of MEs and ADEs in the hospital setting [14-23], most of these reviews have included few or no African studies. There has been no systematic review that broadly assessed the burden of MEs and ADEs in African hospitals. Therefore, the aims of this study were to review the available African-based literature with a focus on: (1) the epidemiology of ADE-related mortality and morbidity; (2) the causality, severity and preventability of ADEs; (3) the magnitude and types of MEs, and their clinical significance, and (4) the main factors reported to contribute to MEs in these studies.

\section{Methods}

\subsection{Definitions}

This study adopted the definition of 'medication error' approved by the National Coordinating Council for Medication Error Reporting and Prevention [24]: "a medication error is any preventable event that may cause or lead to inappropriate medication use or patient harm while the medication is in the control of the health care professional, patient or consumer". Medication errors can occur at any stage of the medication use process, including product labelling, packaging and monitoring. However, this study specifically targets errors occurred at the ordering, transcribing, dispensing and administration stages, and during medication history taking. Various definitions pertaining to each of the ME types are well documented in the international literature $[15,17,20,21]$. We, thus, solely classified studies based on the stage of the medication use process in which an error occurred. The definition of ADE employed in this study was "any injury resulting from medical 
interventions related to a drug," and included both adverse drug reactions (ADRs), in which harm occurs as a result of the intrinsic nature of a medication, as well as complications from MEs [25]. The World Health Organization (WHO) definition of ADR is "a response to a drug which is noxious and unintended and which occurs at doses normally used in man for prophylaxis, diagnosis or therapy" [26]. An injury that is the result of ME is classified as a preventable ADE whereas a non-preventable ADE (also known as an ADR) is an injury other than an error, for example, the occurrence of anaphylactic reactions in a patient with no known previous history of a drug allergy [25]. Another closely related terminology used in pharmacovigilance and epidemiology studies is an adverse event. It generally refers to an unintended injury occurring during medical management, but which does not necessarily have a causal relation to the drug, such as delayed or improper diagnosis [1,2].

\subsection{Data Sources and Searches}

This study used the Preferred Reporting Items for Systematic Reviews and Meta-Analyses guidelines in reporting the results [27]. A systematic literature search was conducted using five electronic databases from inception to 31 August, 2017: PubMed (1946), MEDLINE (1946), EMBASE (1966), Web of Science (1864) and Global Health (1910). We categorised the search terms into three key concepts and combined them using the AND Boolean operator [Appendix S1 of the Electronic Supplementary Material (ESM)]. No year of publication was imposed on the search strategy but was limited to the English language. In some databases, a database-specific limitation was employed as in the Web of Science where article searching was limited to the health sciences field, and abstract availability was considered in the EMBASE and PubMed databases. Additionally, articles were identified by hand searching the bibliographies of included studies, and contact with local medication safety experts was made to identify other relevant published articles. One reviewer (ABM) with the support of a medical librarian carried out the literature search.

\subsection{Study Selection}

The lead author (ABM) screened the titles and abstracts of retrieved studies and evaluated against the inclusion and exclusion criteria. Selected abstracts then underwent fulltext screening. The full texts of studies that were potentially eligible were evaluated by the same primary reviewer, and then the final inclusion was agreed on by two of the authors (AJM, JEB).

\subsubsection{Inclusion Criteria}

We included peer-reviewed original published articles, irrespective of the study design, that investigated the frequency and nature of MEs and/or ADEs. We did not set any limitations on how ME types had been defined in the original research studies. Similarly, the types of events included were overlooked as far as the working definition remained the same, such events range from ADRs to ADEs. Studies that addressed adverse events were included only if injuries due to medications were reported, and data related to these were extracted. The primary outcome of interest was the frequency of MEs (expressed in terms of the number of prescriptions/medication orders/observations with MEs of any type) and/or the proportion of patients who experienced an ADE as a cause for admission or occurred during hospitalisation. Secondary outcomes of interest included an assessment of the nature of ADEs (e.g. fatality and preventability) and MEs (e.g. clinical significance). As we sought to evaluate the African medication safety literature broadly, we also included studies that assessed healthcare professionals' experiences, possible causes of MEs as reported by the original studies. We placed no restriction on the target population, but studies should be carried out in an African hospital setting.

\subsubsection{Exclusion Criteria}

Studies that investigated failures in optimising drug therapy (e.g. drug dosage adjustment in patients with renal failure), pharmaceutical issues (e.g. counterfeit or sub-standard medicines), events caused by single drugs or drug classes (e.g. co-trimoxazole, Antiretrovirals) or disease condition (e.g. human immunodeficiency virus/acquired immunodeficiency syndrome, diabetes mellitus), and studies that aimed to assess knowledge and attitude to ADR reporting were excluded. In addition, studies evaluating non-adherence to medication or self-harm (intentional toxicity) were excluded. Conference abstracts, case studies, commentaries and reviews were not considered in this review.

\subsection{Quality Assessment}

While there are limited approaches for appraising observational studies of ADEs, we assessed such studies for their quality. One review author (ABM) assessed all ADE studies for their methodological quality based on the ten criteria used by Smyth et al. [28]. The main domains considered were study design, methods for identifying ADEs, methods used to establish the causal relationship between drug and effect, and tools for assessing the preventability and severity of ADEs. The quality of ME 
studies was evaluated and reviewed according to the 13 criteria adopted from the previous two studies [20, 29]. Criteria were graded as yes, no, unclear or not reported.

\subsection{Data Extraction and Statistical Analysis}

Data abstraction was performed using a standardised data collection tool, which included study characteristics (publication details, African country, hospital setting, study design, sample size and duration of the study, target population), identification of ADEs and/or MEs (definition, method of data collection, information relating to assessment of causality, severity and preventability) and major findings (the frequency and clinical impact of MEs of any type, prevalence data on ADEs causing admission and occurring in the hospital, including clinical severity and preventability). In studies presenting adverse event data, only data for events due to medications (e.g. drug-related complications and therapeutic errors) were extracted. The most common factors contributing to MEs as reported by the included studies were also extracted.

Adverse drug event studies were reported according to the patient population (paediatric, all ages or adult), and the types of MEs were stratified into sub-categories (prescribing, administration, mixed). We used the term ADE consistently; however, some of the studies provided ADR data. The included studies were heterogeneous, and a metaanalysis was not conducted. However, it was possible to analyse the frequency of ADEs and MEs through calculation of the median occurrence rates and interquartile ranges (IQRs) across studies. For ease of median (IQR) calculation and comparison across the studies, data extracted from the included studies had been converted into a common denominator.

\section{Results}

\subsection{Search Results}

The literature search identified a total of 1316 citations, which included 38 articles identified by hand searching articles (Fig. 1). After removing duplicate citations, title and abstract screening were applied on 1112 articles; of which, 136 were selected for full-text review. Fifty-one articles were finally identified for inclusion in the study (Fig. 1). The most common reasons for excluding articles after the full-text review were ADE prevalence data from specific diseases and/or drugs or classes of drugs, and studies that assessed knowledge and attitude of healthcare professionals for ADR reporting (Appendix S2 of the ESM). Of the 51 studies, 15 reported on ADEs [30-44], 33 reported on MEs (of any type) [45-77], and three studies reported on ADEs and MEs [78-80]. The 51 studies were from nine (of the 54) African countries: Nigeria (16), South Africa (11), Ethiopia (9), Egypt (6), Morocco (3), Ghana and Uganda (each 2), and Sudan and Tunisia (each 1) (Fig. 2).

\subsection{Characteristics of Adverse Drug Event Studies}

Of the 18 included studies investigating ADEs, six were conducted in South Africa and were published between 1979 and 2017. Eleven of the 18 studies were prospective studies, and one was mixed (retrospective and prospective), whereas the remainder were retrospective or cross-sectional studies. A total number of 16,080 patients (excluding mutual patients from Mouton et al. [40] study) were evaluated for ADEs in these studies, mostly in the adult patient population. Four studies [33, 41, 42, 79] clearly reported ADE data for paediatric patients. Female patients comprised $52.2 \%$ of the population $(8097 / 16,080)$. Studies varied in their duration from 5 days to 3 years, and most studies [30, 32, 36, 38-40, 44] were exclusively conducted in the general medical wards (Table 1).

\subsubsection{Quality Assessment of Adverse Drug Event Studies}

Using the assessment criteria adopted from Smyth et al. [28], the quality of ADE studies was evaluated. Four studies [33, 34, 40, 42] met all the ten criteria (Appendix S3 of the ESM). All included ADE studies clearly defined their study design. A variety of methods were used to detect ADEs. The most common method was medical record review [30, 33-40, 44, 79, 80]. Ten studies $[33,34,36,39,40,42,44,78-80]$ used a multifaceted approach for identification of ADEs: a medical record review in combination with other methods, such as voluntary reports, participation in clinical rounds, patient/carrier interview and prescription/laboratory data review. The reported assessment of ADEs with respect to causality, severity and preventability varied among the studies. Causality assessment was described in 15 studies, mostly using the WHO definition [85, 88] (four studies). Severity was measured in 13 studies, mostly using the WHO criteria [82] (three studies) and the same number of studies assessed preventability, predominantly using the Schumock and Thornton method [83] (eight studies) (Table 1). All but three studies [30, 32, 36] provided information about the person responsible for the investigation of the initial ADE detection. Usually a team of physicians, nurses and pharmacists was involved. Verification of the identified ADEs was addressed in eight studies [33-35, 37-41]. The WHO definition [26, 89] of ADRs had been adopted in the majority of studies $[31,34,38,41,42,44]$, but two studies [30, 36] did not 
Fig. 1 Preferred reporting items for systematic reviews of the selection of eligible studies. ADR adverse drug reaction and meta-analyses flow diagram

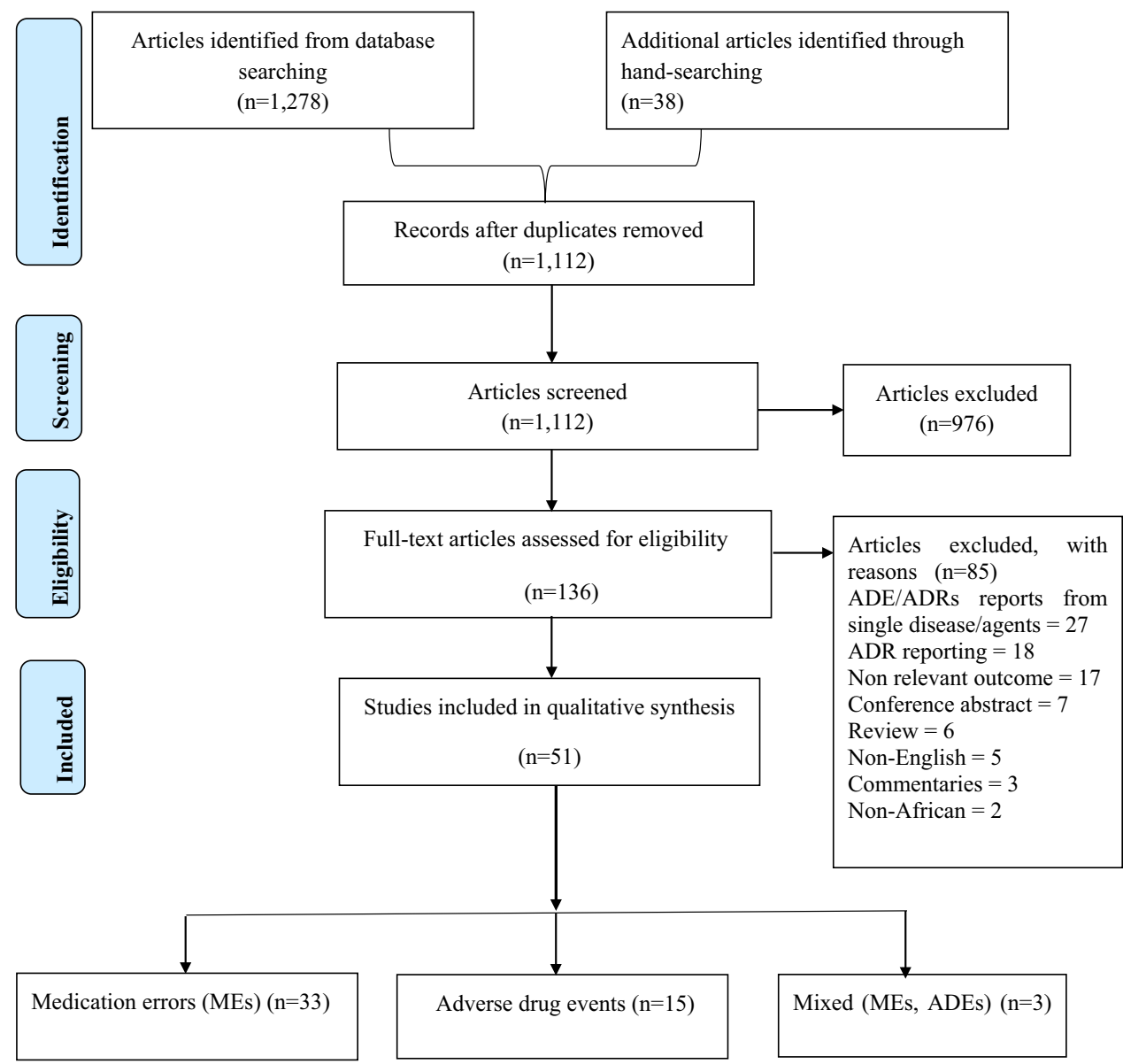

Fig. 2 Graph showing origin of included studies. * one study from Ethiopia and two studies from Morocco gave data for both adverse drug events (ADEs) and medication errors (MEs), and counted as independent studies in this figure

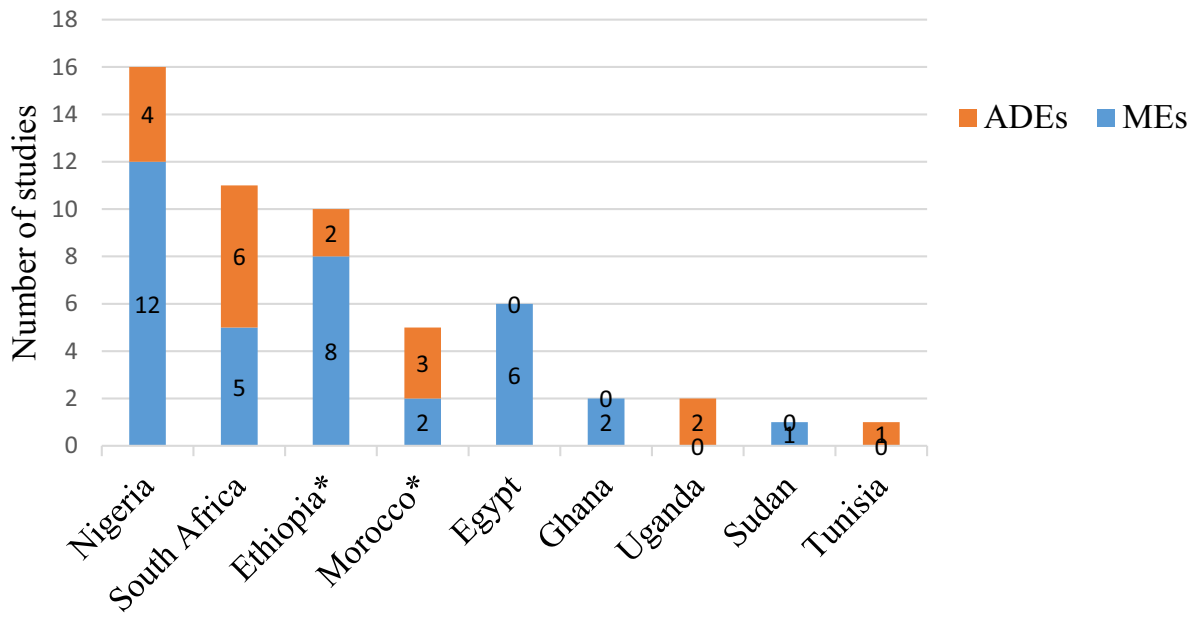

explicitly state the description of an incident (Appendix S4 of the ESM).

\subsubsection{Frequency and Nature of Adverse Drug Events}

\subsubsection{Adverse Drug Events Causing Hospital Admis-} sions A total of 11 studies [30-33, 36, 38, 40-44] involving 12,903 patients reported the number of patients for which an ADE was the primary reason for hospitalisation. Of these studies, three targeted the paediatric population only [33, 41, 42]. In any patient population, the percentage of patients who were admitted as a direct cause of ADEs and not another condition, varied from 0.4\% [41] to $14.3 \%$ [43]. The overall median ADE prevalence showed that $2.8 \%$ (IQR: $0.7-6.4 \%$ ) of patients were admitted in African hospitals as a result of ADEs (Table 2). 


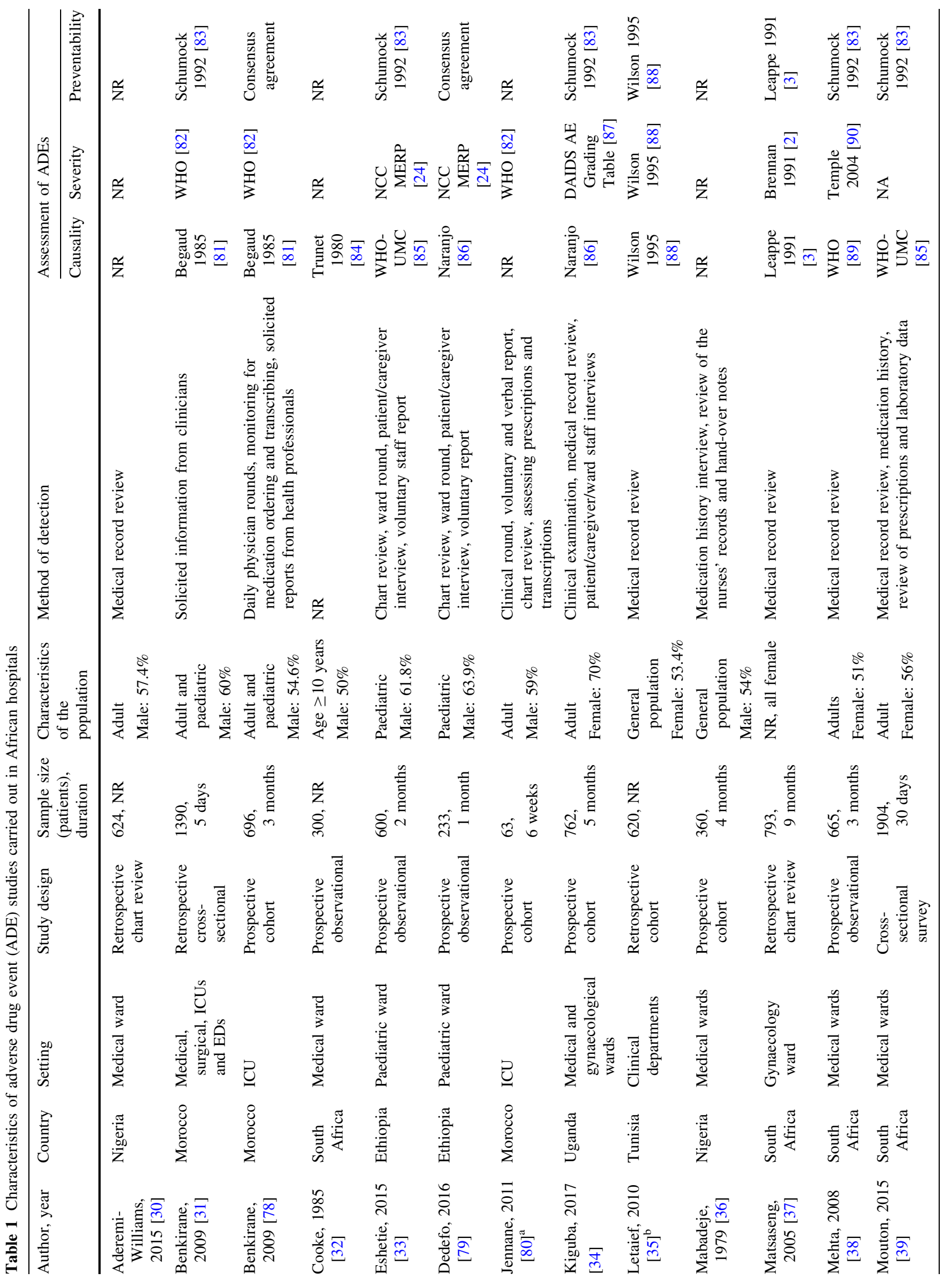




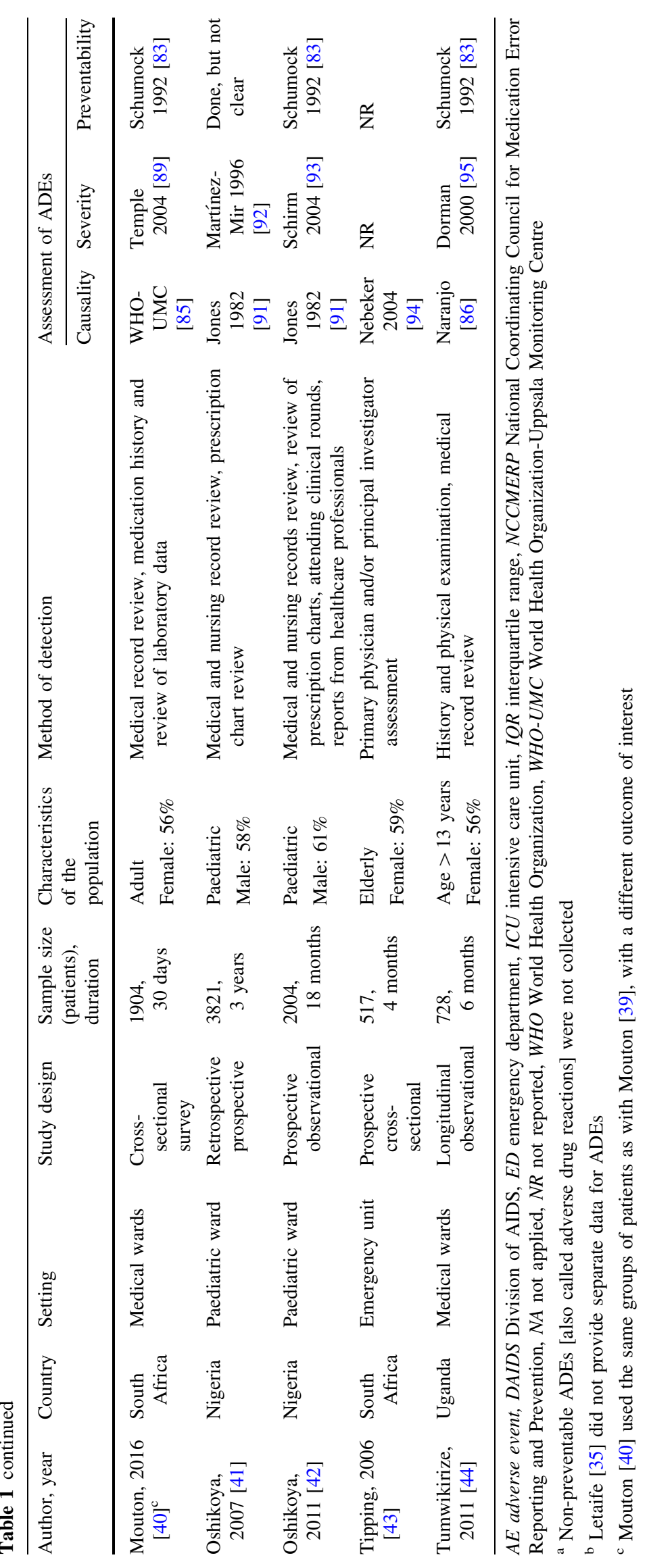


Table 2 Frequency, seriousness and preventability of adverse drug events (ADEs) in African hospitals

\begin{tabular}{|c|c|c|c|c|c|c|}
\hline Author, year & $\begin{array}{l}\text { Prevalence of } \\
\text { ADE-related } \\
\text { admission }(\%)^{b}\end{array}$ & $\begin{array}{l}\text { Incidence of ADEs } \\
\text { during hospitalisation } \\
(\%)^{\mathrm{b}}\end{array}$ & $\begin{array}{l}\text { Prevalence of any } \\
\text { suspected ADE } \\
(\%)^{\mathrm{b}}\end{array}$ & $\begin{array}{l}\text { Proportion of } \\
\text { serious ADEs } \\
(\%)^{c}\end{array}$ & $\begin{array}{l}\text { ADE-related } \\
\text { fatality }(\%)^{\mathrm{b}}\end{array}$ & $\begin{array}{l}\text { Preventability } \\
(\%)^{\mathrm{c}}\end{array}$ \\
\hline $\begin{array}{l}\text { Aderemi-Williams, } \\
2015 \text { [30] }\end{array}$ & 6.4 & 4.3 & & & & \\
\hline Benkirane, 2009 [31] & 1.4 & 4.2 & & 47.5 & 0.1 & 13.2 \\
\hline Benkirane, 2009 [78] & & 11.5 & & 51.8 & 0.3 & 30.0 \\
\hline Cooke, 1985 [32] & 4.6 & & & & & \\
\hline Eshetie, 2015 [33] & $0.7^{\mathrm{a}}$ & $7.7^{\mathrm{a}}$ & & 9.0 & 0.2 & 33.0 \\
\hline Dedefo, 2016 [79] & & 7.3 & & 5.9 & 0.0 & 47.0 \\
\hline Jennane, 2011 [80] & & 12.7 & & 87.5 & 3.2 & \\
\hline Kigbua, 2017 [34] & & 25.0 & & 31.0 & 0.0 & 55.0 \\
\hline Letaief, 2010 [35] & & $2.7^{\mathrm{a}}$ & & NS & NS & NS \\
\hline Mabadeje, 1979 [36] & 2.8 & 13.1 & & & & \\
\hline Matsaseng, 2005 [37] & & $9.8^{\mathrm{a}}$ & & NS & NS & NS \\
\hline Mehta, 2008 [38] & 6.3 & 6.3 & 8.4 & $50.4^{\mathrm{a}}$ & $0.3^{\mathrm{a}}$ & 46.0 \\
\hline Mouton, 2015 [39] & & & & & 2.9 & 43.5 \\
\hline Mouton, 2016 [40] & $8.5^{\mathrm{a}}$ & & & 23.5 & d & 45.0 \\
\hline Oshikoya, 2007 [41] & 0.4 & 0.7 & & SG & 0.1 & 97.7 \\
\hline Oshikoya, 2011 [42] & 0.6 & 1.1 & & SG & 0.1 & 20.0 \\
\hline Tipping, 2006 [43] & $14.3^{\mathrm{a}}$ & & 20.1 & & & \\
\hline Tumwikirize, 2011 [44] & 1.5 & 49.5 & 4.5 & 0.0 & 0.0 & 4.1 \\
\hline Median (IQR) & $2.8(0.7-6.4)$ & $7.5(4.3-16.1)$ & $8.4(4.5-20.1)$ & $23.5(9.0-50.0)$ & $0.1(0.0-0.3)$ & $43.5(20.0-47.0)$ \\
\hline
\end{tabular}

$I Q R$ interquartile range, $N S$ no specific data available, $S G$ only severity grading reported

${ }^{a}$ Not provided directly in the study, interpreted from other presented data

${ }^{b}$ The total number of patients was used as a denominator in the respective studies

${ }^{c}$ The total number of reported ADEs was used as a denominator in the respective studies

${ }^{\mathrm{d}}$ Mortality data from the Mouton et al. study [40] were already used in the calculation of the mortality rate by their previous study [39] and are not presented here

After the exclusion of studies that reported data on the paediatric population only, the median prevalence estimate was found to be $5.5 \%$ (IQR: $1.8-8.0 \%$ ).

\subsubsection{Any Suspected Adverse Drug Events at Hospital} Admission Three studies [38, 43, 44] estimated the percentage of patients experiencing any ADEs, which may or may not be the cause for hospitalisation, at the time of hospital admission. Of the total 1900 patients evaluated for any suspected ADEs at hospital admission, at least one ADE was identified in 192 patients, and the overall median prevalence of any suspected ADEs in these studies was 8.4\% (IQR: 4.5-20.1\%) (Table 2).

\subsubsection{Adverse Drug Events during Hospitalisation No} separate ADE data were reported in one study [35]; the aim was not primarily an assessment of ADEs. Fourteen studies [30, 31, 33-38, 41, 42, 44, 78-80] reported the occurrence of ADEs during hospitalisation. The percentage of patients who developed at least one ADE during a hospital stay ranged from $0.7 \%$ [41] to $49.5 \%$ [44], with an overall median incidence of $7.5 \%$ (IQR: $3.8-12.8 \%$ ) (Table 2). After the exclusion of studies carried out solely on the paediatric population, the median percentage for this outcome was reported to be $10.7 \%$ (IQR: 4.3-16.1\%).

\subsubsection{Severity and Seriousness of Adverse Drug Events}

Thirteen studies [31, 33-35, 37, 38, 40-42, 44, 78-80] assessed the seriousness and/or severity of an ADE; however, data for two studies [35, 37] were not available as ADE-specific data were not provided. Assessment of clinical severity varied among the included studies, and one study [34] clearly made a distinction between severity and seriousness measurement, and two studies [41, 42] reported the severity of ADEs only. Many studies (9/13) reported the seriousness of ADEs, but this was also assessed variably, and thus, for ease of analysis, we broadly classified serious ADEs (like Symth et al. [28] did) as those that caused either death or were life threatening, resulted in 
permanent disability or hospital admission or prolonged hospitalisation. Of the 9 studies, one study [44] did not report serious events during admission and/or hospitalisation, and the remainder included serious ADEs of various rates: $5.9 \%$ [79] to $87.5 \%$ [80] of all ADEs. The median proportion of serious ADEs reported by all the nine studies was $31.0 \%$ (IQR: $7.5-51.1 \%$ ) of all ADEs (Table 2). The median occurrence of serious ADEs, when paediatric-only studies were excluded, was found to be $47.5 \%$ (IQR: 23.5-51.8\%).

Only one study from South Africa [39] entirely focused on mortality associated with ADRs, investigating the proportion of deaths attributed to ADRs in medical in-patients at four hospitals through a review of medical notes, medication exposure (during the previous 30 days) and laboratory data. This study estimated that ADEs contributed to the death of $2.9 \%$ of hospital admissions, and $16 \%$ of all hospital deaths were attributed to ADEs [39]. In the remainder of studies, the mortality rate associated with ADEs was reported as a secondary outcome of interest. In general, no fatal ADEs were reported in three studies [34, 44, 79], and nine studies [31, 33, 38-42, 78, 80] reported fatal ADEs in 68 of 12,866 patients included in the analysis. In the general population, the median mortality rate attributed to ADEs was estimated to be $0.1 \%$ (IQR: $0.0-0.3 \%$ ) (Table 2). However, when the paediatric data were excluded, deaths associated with ADEs was reported in a median of $0.3 \%$ (IQR: $0.0-2.9 \%$ ) of all patients.

\subsubsection{Preventability of Adverse Drug Events}

Thirteen studies [31, 33-35, 37-42, 44, 78, 79] performed a preventability assessment for ADEs describing a variable preventability of 4\% [44] to $97.7 \%$ [41] of all events. However, data for Letaief et al. [35] and Matsaseng and Moodley [37] were not available as ADE-specific data could not be extracted, but showed a preventability of 60 and $55 \%$, respectively, in the overall incidence of adverse events. The median percentage of preventable ADEs reported by all the remaining 11 studies was $43.5 \%$ (IQR: 20.0-47.0\%) of all ADEs (Table 2).

\subsection{Characteristics of Medication Error Studies}

Of all the $36 \mathrm{ME}$ studies (including those evaluated both MEs and ADEs), ten studies did not specify the type of MEs; 14 studies evaluated medication administration errors and 12 studies assessed prescribing errors. No studies were identified that specifically reported transcribing errors, dispensing errors and medication history errors. Most studies (12/36) were conducted in Nigeria and 8 studies $[55,60,62,67-69,74,78]$ were conducted in a multicentre setting. Five studies [50, 52, 56, 65, 79] were solely conducted in a paediatric ward and one study [73] in an obstetric ward. Two pre-post studies were identified $[49,50]$, and the remaining were either observational studies (prospective or retrospective) or quantitative/qualitative surveys. Of these, eight questionnaire-based studies and two mixed-method studies were identified (six administration errors, three prescribing errors, one mixed error) to evaluate MEs reported by various healthcare professionals (Table 3 ).

\subsubsection{Quality Assessment of Medication Error Studies}

After the application of the quality assessment criteria against ME studies, criteria appropriate for any ME study, no study met all the 13 criteria. One study (each) fulfilled 12 and ten criteria, 2 studies met 9 criteria and 8 studies met eight criteria. The remaining studies met seven or fewer criteria (Appendix S3 of the ESM). The type of MEs was not specified in ten studies, and various definitions for ME were used in the included studies (Appendix S4 of the ESM). Eleven studies did not describe adequate details of MEs, and studies differed in methods for identifying MEs. The majority of the studies employed a prescription review (to identify prescribing errors) and observations (for assessing medication administration errors) but one study [61] did not explicitly report the method of error detection (Table 3).

\subsubsection{Frequency and Nature of Medication Errors}

3.3.2.1 Medication Errors (Mixed) All but one study [74] that assessed MEs of any type were able to report details of the error rate. However, these data were difficult to summarise as error rates were presented in different ways. For example, MEs were reported in 75\% [79] to 97\% of patients [76], 10-54.8\% of medication orders [72, 80], $4.2 \%$ of prescriptions [73] and $2.9 \%$ of medication doses [75]. Additionally, the incidence of MEs were reported in 7.5-7.8 per 100 admissions [78, 80], 7.7-9.7 per 1000 patient-days [78, 80] and 40.5 per 100 person-years [71]. Six studies $[73,75,77-80]$ explicitly described the stage at which errors were occurred in the medication use process. Most errors were identified during prescribing, median (IQR): $41.3 \%$ (26.8-58.3\%) [73, 75, 77-80] followed by the administration stage, median (IQR): $20.6 \%$ $(12.5-41.6 \%)[73,75,77-80]$ and then the monitoring stage, median (range) $16.7 \%(8.4-25.0 \%)$ [77, 79].

3.3.2.2 Prescribing Errors Studies that addressed prescribing errors reported a median error rate of $57.4 \%$ (IQR: $22.8-72.8 \%$ ) of all prescriptions $[45,51,52,54]$ and $40.0 \%$ (IQR: $8.8-49.5 \%$ ) of medication orders [46, 49, 53, 54, 56] (Fig. 3). 


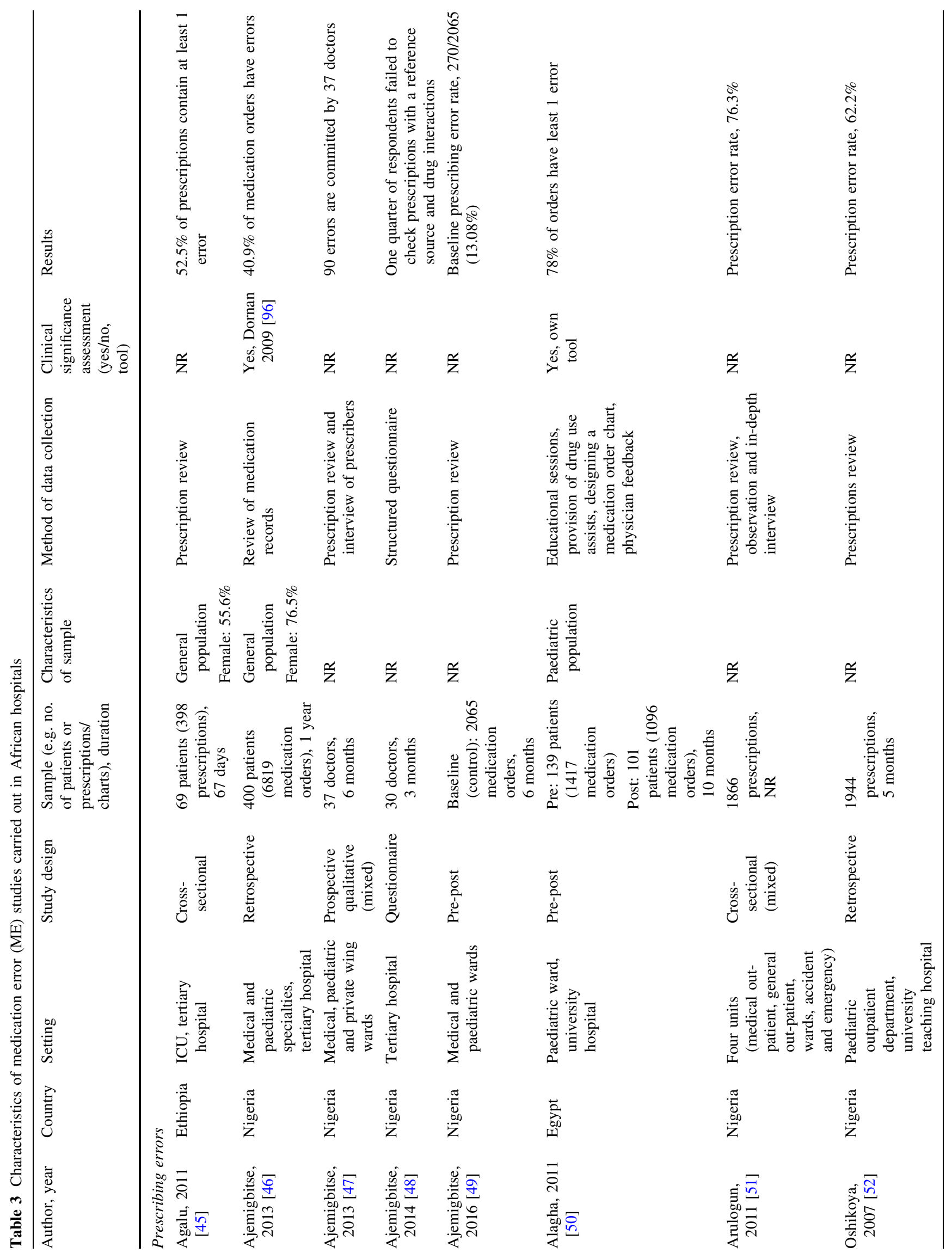




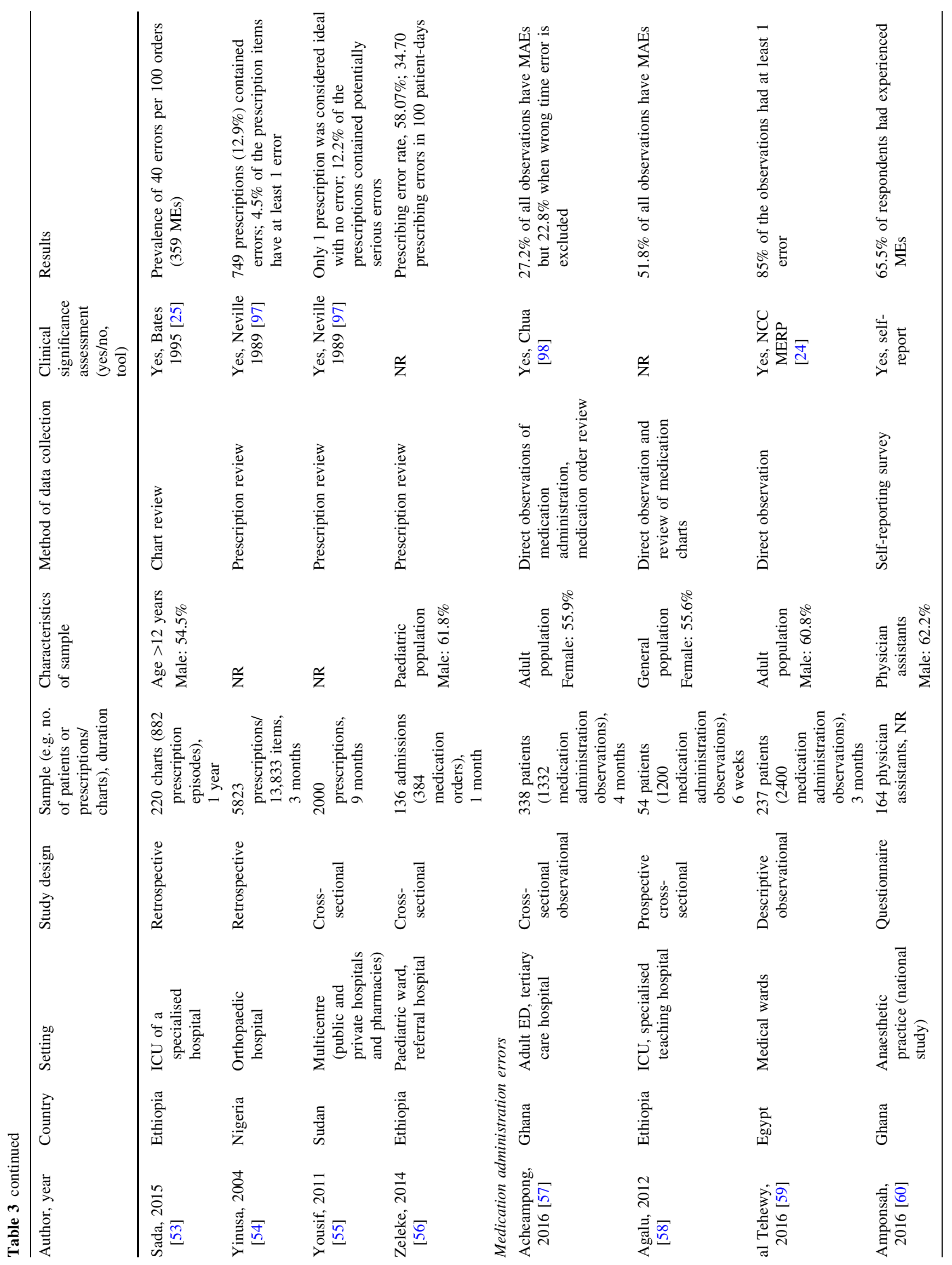




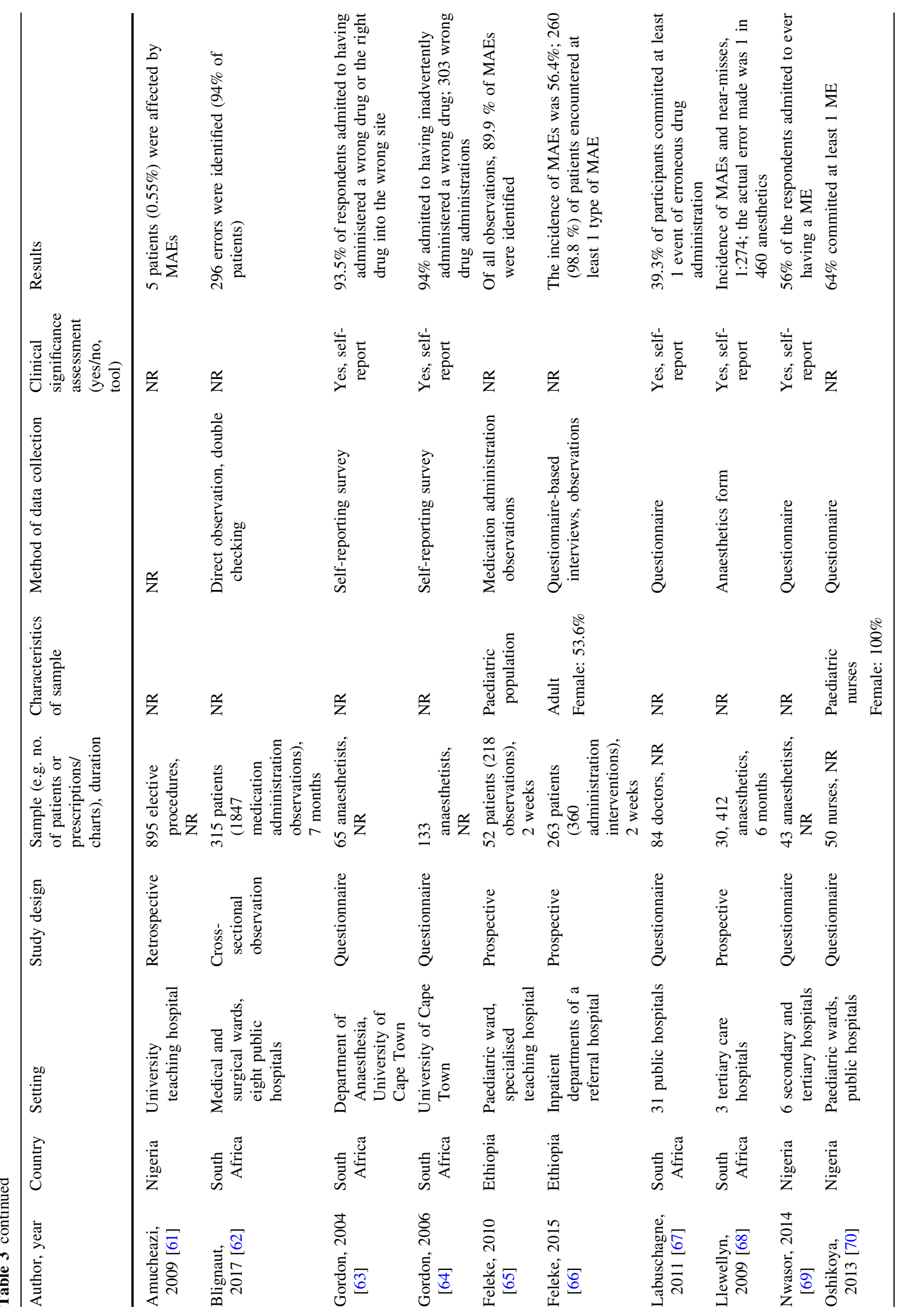




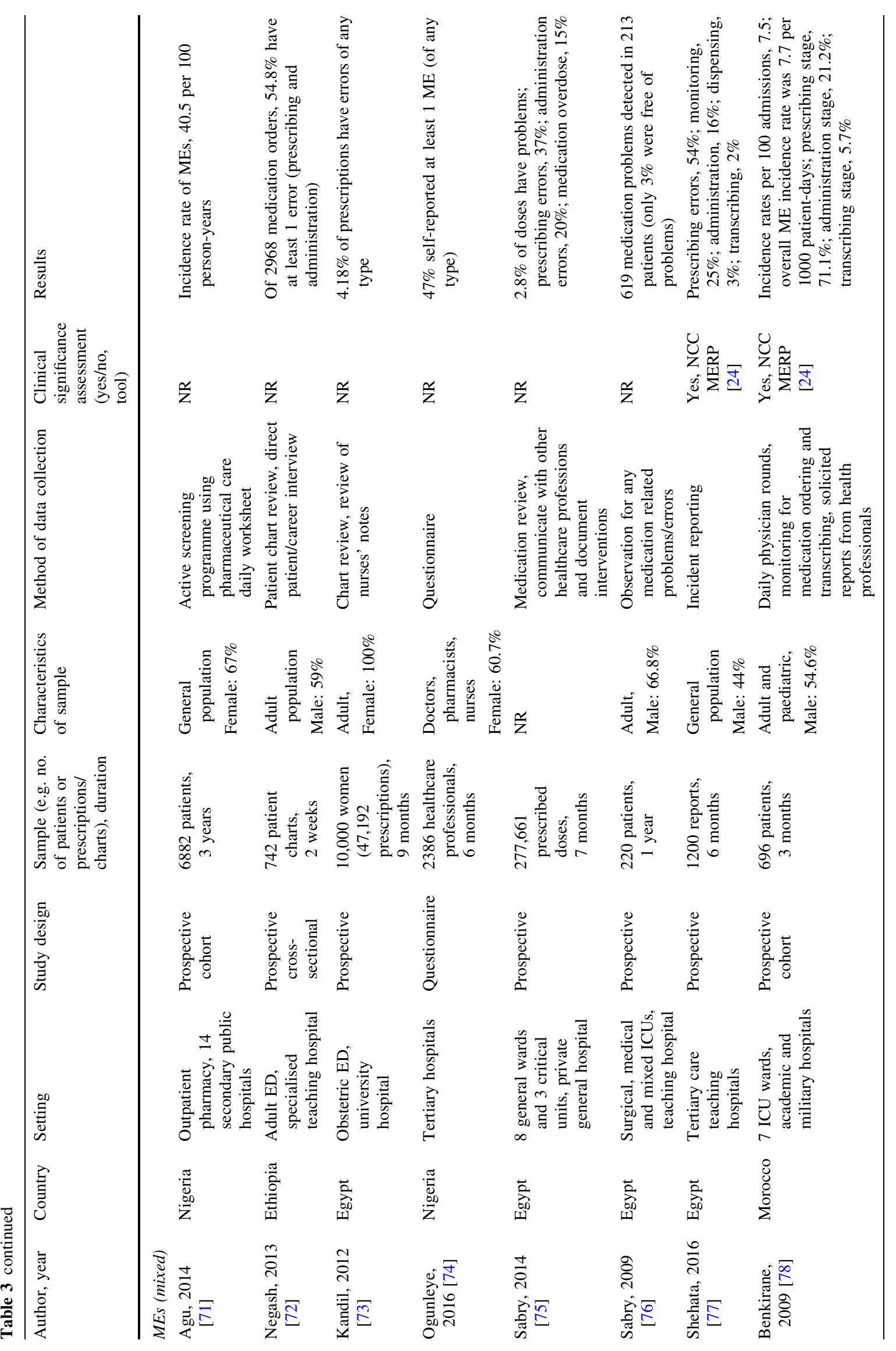




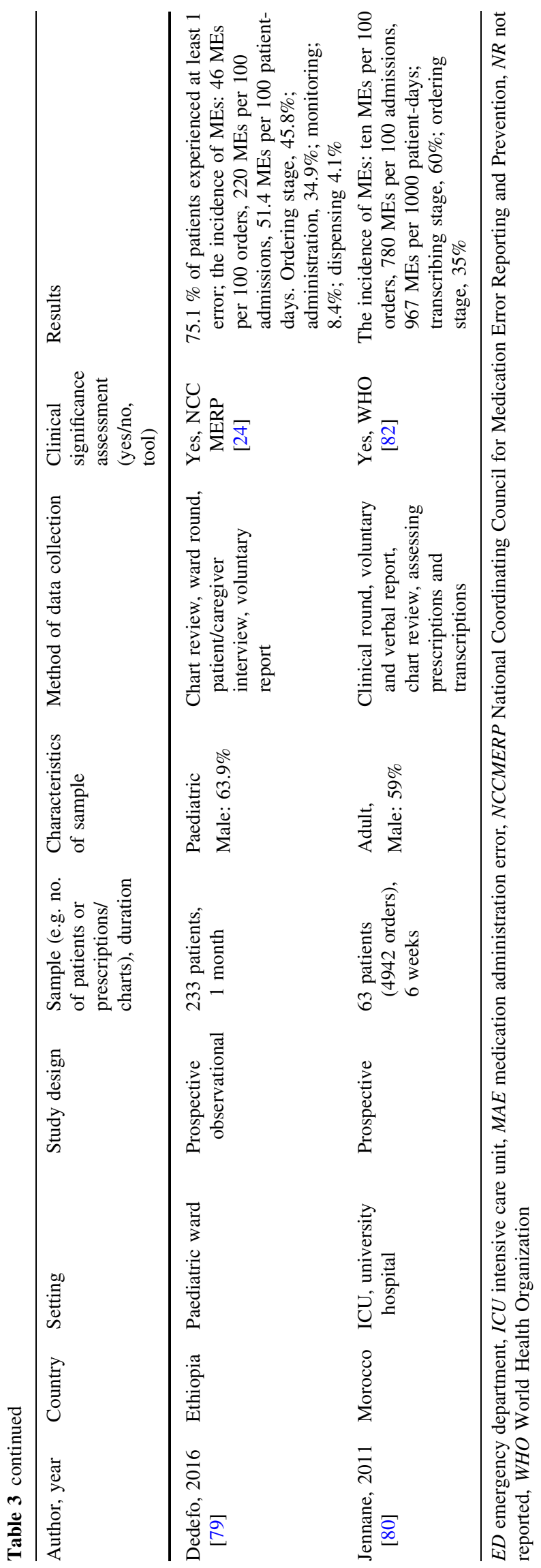

Prescribing error rate, $\%$

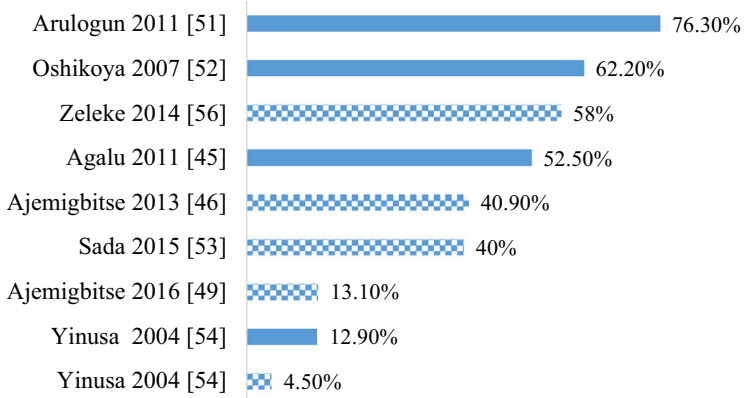

$100 \%$

Fig. 3 Graph showing the extent of the prescribing error rate in African hospitals. Light bars indicate total medication orders used as denominators for error calculation. Solid bars indicate total prescriptions used as denominators for error calculation

3.3.2.3 Medication Administration Errors Eight studies $[57-59,61,62,65,66,68]$ calculated medication administration error rate. A study by Amucheazi and Ajuzieogu [61] analysed only a single component of the medication administration procedure in an anaesthetic department, with incorrect drug administration reported in $0.5 \%$ of elective surgical procedures. A study by Llewellyn et al. [68] has reported an administration error incidence of one in 274 anesthetics administered. These events were further consolidated from self-reports [60, 63, 64, 67, 69] showing that 39-94\% of doctors/anaesthetists/physician assistants reported at least one medication administration error in their career. Other than anaesthetic administration errors, one questionnaire-based study [70] of a paediatric nurse's experience of medication administration errors reported that $64 \%$ of nurses described at least one error over the course of their career. Overall, at least one medication administration error has been reported in a median of $56.4 \%$ (IQR: $39.5-87.5 \%$ ) of all medication administration observations $[57-59,65,66]$.

\subsubsection{Types of Medication Errors}

The most common type of errors reported in the reviewed studies was greatly influenced by the methodological approach, and there were also various classifications of error types depending on the medication use process. In general, all but five studies [47, 55, 61, 64, 67] included some details regarding the most common types of errors in their report. Of these, 29 of the 31 studies identified the type of MEs reported commonly and was a prescription and/or an administration for an incorrect dose. Other commonly reported errors included wrong drug combination and/or selection (21/31), wrong route of administration (17/31), omission errors (15/31) and wrong frequency and/ or duration (11/31) (Table 4). 


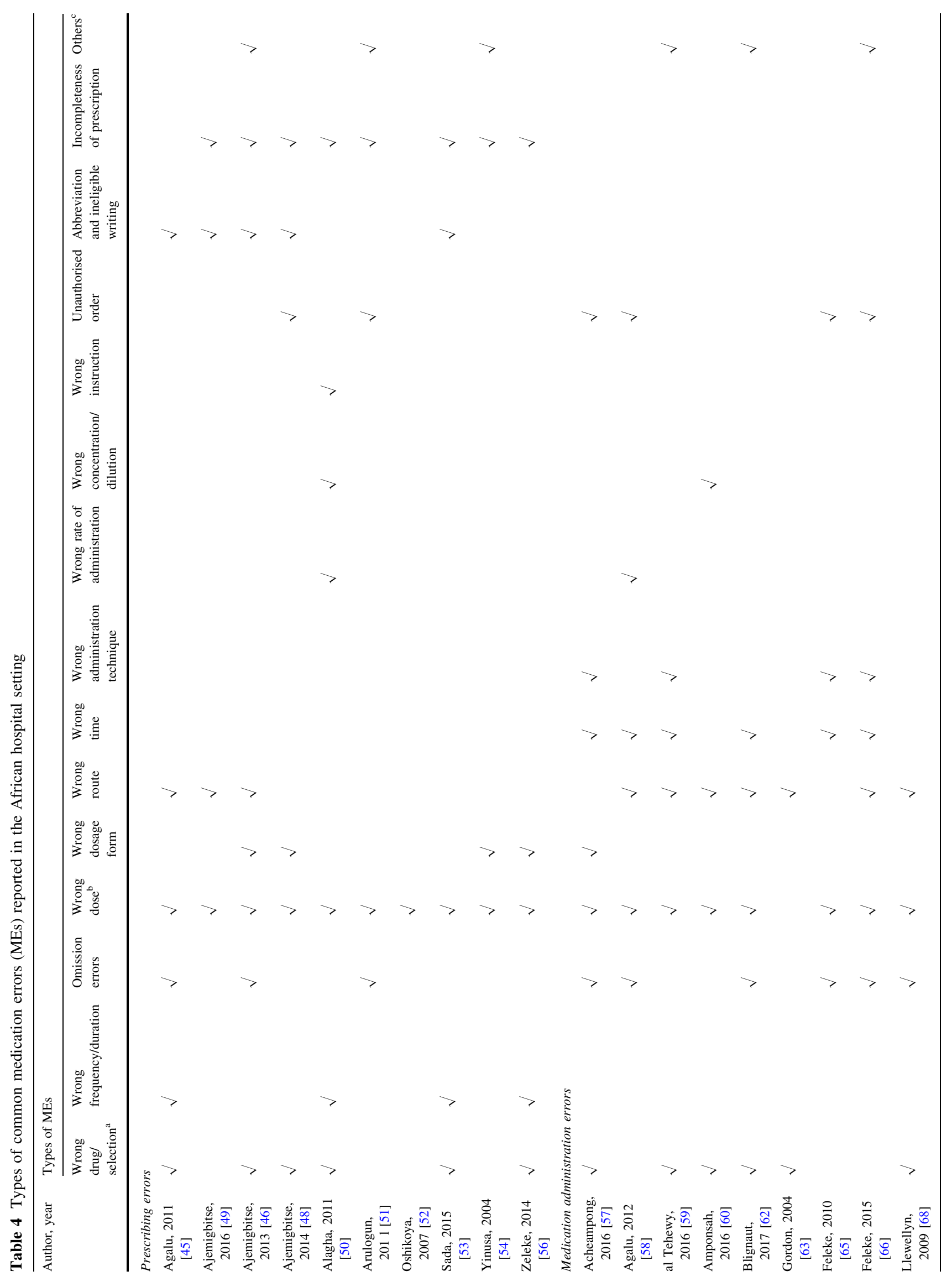




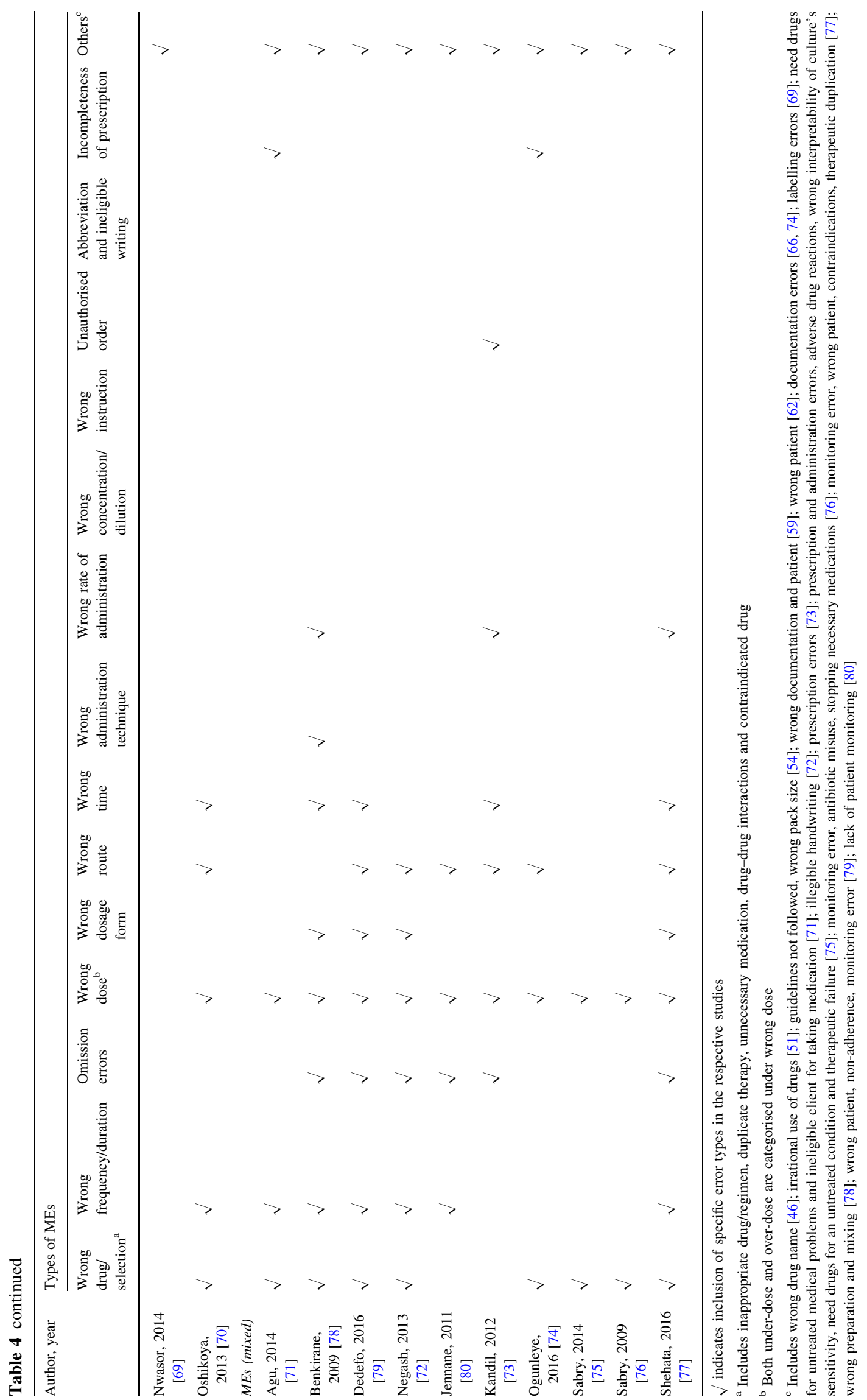


Fig. 4 Graph illustrating the percentage of prescriptions or medication orders or medication administrations with dosing errors in African hospitals. Light bars indicate the study used the total number of medication orders as a denominator to calculate dosing errors. Solid bars indicate the total number of prescriptions and white bars indicate the total number of medication administrations as denominators for dosing errors

\section{Dosing error rate, \%}

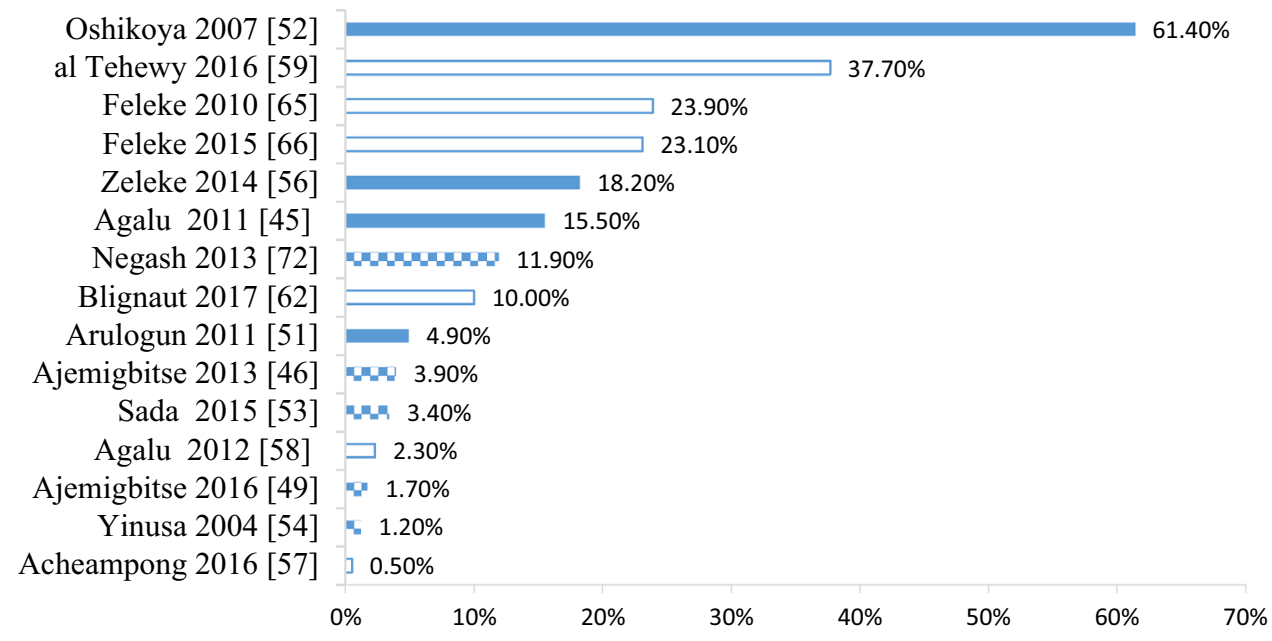

Specifically, error rates among the studies were greatly affected by the definitions pertaining to MEs (of any type). In studies with a broader error definition, including the completeness of a prescription (e.g. dosage form, age of a patient, legalisation of the prescription), a higher error of this type was reported in the respective studies. Negash et al. [72], for example, have shown that there were no medication orders described on the dosage form on the prescription. Similarly, other studies $[47,51,54,56]$ also reported the provision of incomplete prescribing information (incomplete description of prescription items, omission of duration, legality of prescription) in $52-86 \%$ of all prescriptions. This review revealed that MEs of any type associated with dosing problems have been shown in a median of $14.2 \%$ (IQR: $7.8-21.7 \%$ ) of all errors. Specifically, a median of $15.5 \%$ (IQR: $7.5-50.6 \%$ ) of the prescriptions and $3.4 \%$ (IQR: $1.5-7.9 \%$ ) of the medication orders, and $16.6 \%$ (IQR: 1.9-27.4\%) of the medication administration observations were reported to contain dosing errors (Fig. 4).

\subsubsection{Clinical Significance of Medication Errors}

Most of the studies did not investigate the clinical impact of the reported MEs. Excluding those studies that measured consequences of MEs through self-reports, 11 studies addressed the impact of MEs [46, 50, 53-55, 57, $59,77-80]$. However, these studies varied in terms of measuring tools for the clinical significance of errors. Of all the MEs collated, only four fatal errors from three studies [57, 78, 80] were reported, and in six studies $[46,53,54,57,78,80]$, the median percentage of clinically serious MEs (defined as errors with a potential to cause death, and were life threatening or resulted in permanent disability or prolonged hospitalisation [28]) were identified in 5.1\% (IQR: 1.7-29.2\%) of MEs. Data from self-reports $[63,67-69]$ also showed that most of the errors committed by healthcare professionals were trivial and would not have resulted in deaths.

\subsection{Factors Contributing to Medication Errors}

Investigating the factors that contributed to MEs was the focus of 15 studies [47, 48, 55, 57, 60, 63, 64, 67, 69, $70,74,75,77-79]$. Only one qualitative study [47] using human error theory uncovered the causes of prescribing errors committed by junior medical doctors in an in-patient setting. In contrast, 9 of the 15 studies [48, 55, 60, $63,64,67,69,70,74]$ employed self-report data to assess the possible causes of MEs as a whole, causation data from four studies [57, 75, 77, 78] were based on individual errors, and it was not clear how these data were collected in one study [79]. The factors most commonly cited as contributory to MEs were individual factors (e.g. fatigue and inadequate knowledge/training), working environment (e.g. distraction and high workload) and task (e.g. lookalike names and labelling deficits) (Table 5).

\section{Discussion}

\subsection{Main Findings}

This is the first systematic review of the burden and nature of MEs and ADEs in African hospitals. This study was able to identify 51 studies in nine African countries; of these, 18 assessed ADEs. In any patient population, the median prevalence of any suspected ADE on hospital admission (that could likely or unlikely lead to admission/hospitalisation) was $8.4 \%$ while a median of $2.8 \%$ of patients were 


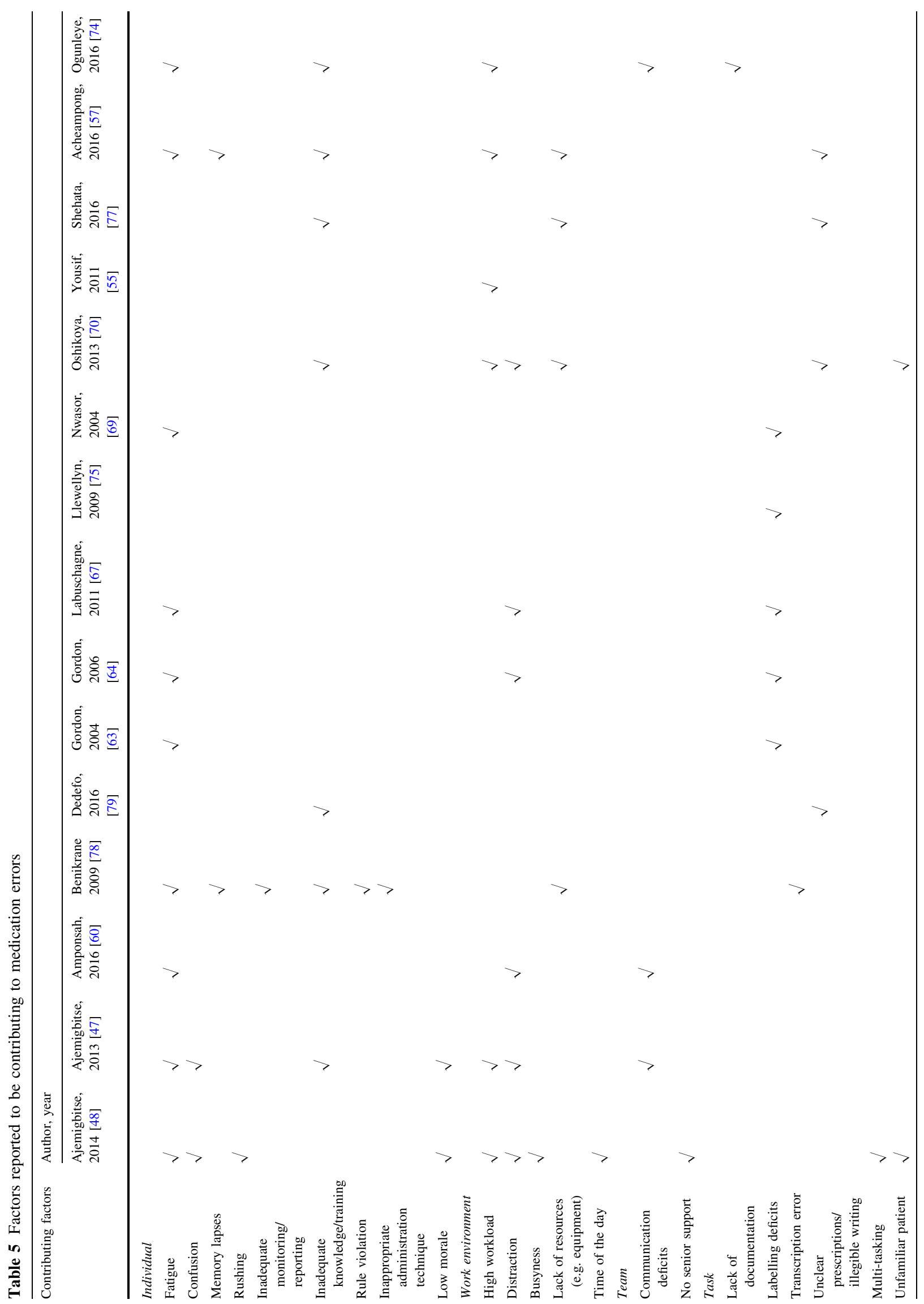




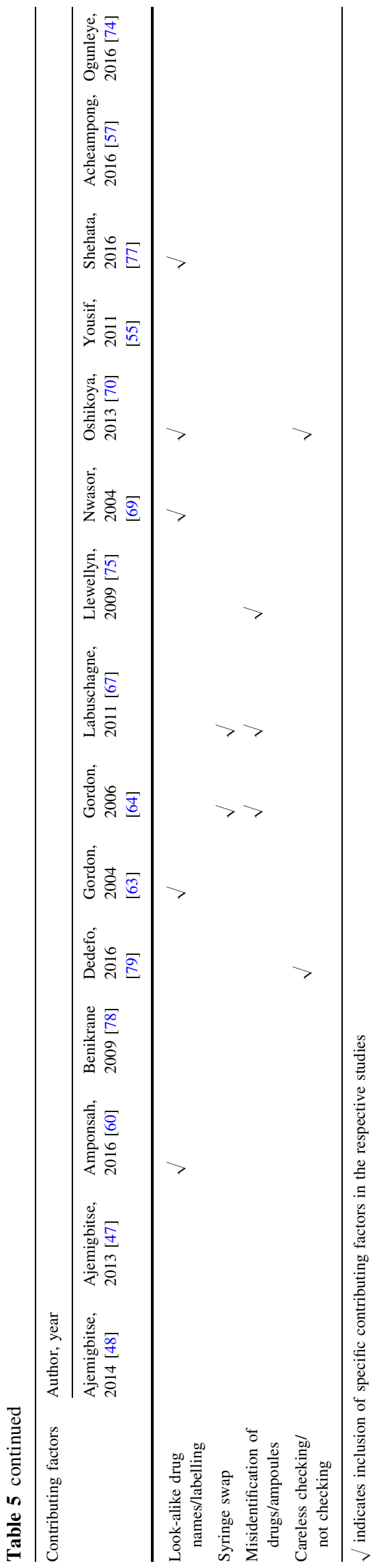

admitted as a direct cause of ADEs. Adverse-drug eventrelated fatalities were relatively uncommon but the rate varied across the studies considerably, and it was reported that close to $44 \%$ of the ADEs were deemed preventable. It was reported that the rate of MEs was high, and most commonly occurred at the stage of prescribing. Dosing errors have been frequently reported; however, many of the errors were clinically insignificant. A range of factors contributing to MEs has been described in African hospitals including fatigue, lack of knowledge and training, high workload and workplace distraction.

\subsection{Comparison with Existing Literature}

There is a lack of high-quality studies with rigorous designs that investigate medication safety in African hospitals. In fact, the study of MEs can be considered a relatively new area of research as studies have only emerged since 2004 [63], although research on outcomes from ADEs dates back to the 1970s [36].

Although there was a wider variation in the definition, method of detection and assessment, this review has shown that African hospitals reported a higher rate of MEs than similar reviews conducted on data mainly from developed countries [15-17] but was consistent with other reviews from the Middle East [20, 21] and Southeast Asia [29]. In the present study, the majority of the studies evaluated medication administration errors; however, the prescribing stage is the stage at which the highest error rate occurred in African hospitals. Other reviews have also demonstrated that prescribing errors were the most common MEs to occur in the hospital setting [17, 20]. However, a review of the extent of MEs in Iran reported that medication administration errors were the most commonly reported types of errors [21]. This difference may be owing to the high number of studies that evaluated medication administration errors in that review (83\% of the studies). A previous systematic review [20] from Middle Eastern countries reported an incidence of prescribing errors in $7.1-90.5 \%$ of prescriptions, which is comparable to the present study examining African hospitals. However, a review [17] of studies from USA or the UK (72\% of the studies) reported a lower rate of prescribing errors (2-14\%). Similarly, the rate of administration errors in this study is comparable to that from Middle Eastern countries (9.4-80\%) [20, 21] and Southeast Asia (15.2-88.6\%) [29] but higher than that reported from developed countries (8.6-28.3\%) [15].

In the present study of medication administration errors, the surgical/anaesthetic department has shown a different pattern in terms of the frequency and nature of incidents reported. Only a single component of the medication 
administration procedure; that is, wrong medication administration with an emphasis on anesthetic medications only were reported, and much of the concern was because of a syringe swap or syringe/drug misidentification of anaesthetics. A lower incidence of MEs in anaesthesia was reported, and this may be expected and consistent with other studies $[99,100]$, as this may be considered a relatively safe environment, but still over two thirds of doctors/ anaesthetists/physician assistants reported making at least one error during their career.

Regardless of the medication use process, dosing problems were the most commonly reported types of errors, which is supported by previous reviews [20,21]. This study has identified most errors were clinically insignificant. In the extreme, there were also medication-related fatalities not reported in previous reviews $[15,20,21]$ or reports from developed countries [101, 102]. However, the prevalence of ADE-related admission aligns with data from the international literature $[12,13,22,23]$. For example, a systematic review of European studies [23] has identified individual studies with the highest fatal ADRs in $0.49 \%$ of all patients admitted because of ADRs, which is lower than that reported in our review (2.9\%). Unlike the pattern in developed countries, a larger proportion of ADE-related deaths in Africa is mostly the result of medications used in the treatment of human immunodeficiency virus and tuberculosis [38, 39], also reflecting the high burden of these diseases in the African hospital setting.

Many systematic reviews have estimated the proportion of patient admissions attributable to ADEs to range between 2 and 5.3\% [12, 13, 22, 23, 28]. Our median ADE estimate for ADEs that occurred during hospitalisation is close (only when the paediatric studies were excluded) to an estimate from another systematic review of ADRs in the elderly, which has reported an ADR prevalence of $11.5 \%$ [103]. Our finding that many of the ADEs were deemed preventable is in line with a systematic review by Hakkarainen et al. [104], which estimated that 52 and $45 \%$ of the ADEs are preventable in the adult outpatient and inpatient settings, respectively. This highlighted the importance of designing appropriate prevention strategies for the best possible reduction in medication-related harms.

\subsection{Strengths and Limitations}

The main strength of this study was the exploration of the medication safety literature with broader inclusion criteria (consisting of ADEs and MEs) across a range of hospital settings in Africa. No limit on the year of publication was applied, and also an extensive search of articles was done. For example, our study identified studies that were not included in previous systematic reviews, such as in the Leendertse et al. study [105], which includes only one African study. Furthermore, our search strategy was able to identify many relevant studies not previously located.

However, the strengths of the results and evidence base presented in this review depend on the strength of data collected from the individual study. For instance, validity and reliability of ADE detection were infrequently reported, and the majority of studies relied on an initial single screening phase without further verification from an independent review. Studies often lacked a valid assessment tool to help establish causality between medication misadventures/harms and the offending agent, and the same for preventability and severity. There were also heterogeneities among the included studies with regard to the methods used to detect ADEs and their definition, which may be one of the reasons for a wide range of individual estimates. Over half of the studies did not provide a working definition of a ME nor described components of a ME. Additionally, different definitions of a ME were used among the studies, and there was variability in the typology of MEs, for example, some studies excluded dosage form errors, illegibility and legalisation of the prescription. There was also a wide variation in the methods of data collection, and inconsistencies in ME assessment and reporting, leading to difficulties in estimating the rate of MEs.

We did not perform a thematic analysis for causes of errors in this study. This was because there was heterogeneity in the way studies reported these data, and mainly the data were extracted from questionnaire-based studies. There was only one study that used a human error theory for explaining error causes, and for ease of simplicity, we summarised error causes as individual, work environment, team and task factors. Furthermore, the quality of these studies was judged grossly and not on an outcome basis. Another potential limitation of this study is the restriction of the search to published literature and English language. Limiting the search to the English language might contribute to our few included studies; notably, publications from French-speaking countries might delimit the number of articles included in the present study. Apart from language, the African content is characterised by a diverse geographical area and thus, caution should be taken in the interpretation of our findings. It should also be noted that the scanning of titles and abstracts of the search results was performed by a single researcher. However, our review was comprehensive and because there has been no published review addressing these issues in Africa, this review sheds light on the extent of MEs and their associated harms in the African hospital setting. 


\subsection{Implications for Future Research}

This review highlights that African hospitals share much of the challenges in the medication safety literature observed across the globe. A challenge in reviewing these studies is that, there is no universally accepted method for either causality assessment of ADEs [106] or estimation of its preventability [107], nor a denominator for error rate reporting [108] and a tool for severity measurement [109]. However, when designing patient safety programmes specifically targeting MEs and their misadventure, it is essential that future studies should assess the causality, preventability and clinical consequences associated with them. More importantly, the effectiveness of medication safety programmes designed to reduce errors requires these tools for complete evaluation. Unfortunately, in our review, only two pre-post studies were retrieved that aimed to decrease the frequency of prescribing errors.

In countries with better resources, medication safety programmes are well integrated with the healthcare system $[110,111]$. In developing countries like many in Africa, however, healthcare coverage is prioritised to medication safety, and the medication use system is not evidence based [33]. However, the medical community believes in the need to implement strategies to protect patients from medication harms. This warrants interventional programmes to be tested despite the resource limitations. Of the various strategies, adoption of electronic prescribing [110] and greater targeted involvement of pharmacists [111-113] in care teams are documented internationally. Currently, there is also an influx of information technology in the African healthcare system [114], and an extension of a pharmacist's role in patient care [115], which could lead to a momentous change in medication safety programme implementation. Furthermore, individual factors, such as knowledge deficits, were described as a major contributing factor for medication incidents; thus, educational sessions may be essential as a preventive strategy and should be evaluated in future studies. No studies that specifically assessed transcribing errors, dispensing errors and documentation errors in African hospitals were retrieved.

\section{Conclusion}

This review has found that there have been limited reports on medication safety in African countries in the past, but this is increasing over time. There is, however, a lack of high-quality studies with rigorous designs that investigate the frequency and nature of MEs and ADEs. Based on the current literature, ADEs are an important cause of morbidity in African hospitals, both on admission and during hospitalisation, but many are deemed preventable.
Medication errors are common and mostly occur at the prescribing stage. Dosing errors are frequently reported, but many of the reported errors are clinically trivial. There is a paucity of information on other types of errors, such as dispensing, transcribing and documentation errors. Designing preventive strategies to target the most likely contributing factors is of paramount importance.

Acknowledgements Alemayehu B. Mekonnen gratefully acknowledges funding to support his $\mathrm{PhD}$ training provided by The University of Sydney International Students' Scholarship. The authors acknowledge the support provided by King Saud University, Vice Deanship of Research Chairs.

\section{Compliance with Ethical Standards}

Funding This research received no specific grant from any funding agency in the public, commercial or not-for-profit sectors.

Conflict of interest Alemayehu B. Mekonnen, Tariq M. Alhawassi, Andrew J. McLachlan, and Jo-anne E. Brien have no conflicts of interest directly relevant to the content of this article.

Open Access This article is distributed under the terms of the Creative Commons Attribution-NonCommercial 4.0 International License (http://creativecommons.org/licenses/by-nc/4.0/), which permits any noncommercial use, distribution, and reproduction in any medium, provided you give appropriate credit to the original author(s) and the source, provide a link to the Creative Commons license, and indicate if changes were made.

\section{References}

1. Benjamin DM. Reducing medication errors and increasing patient safety: case studies in clinical pharmacology. J Clin Pharmacol. 2003;43:768-83.

2. Brennan TA, Leape LL, Laird NM, Hebert L, Localio AR, Lawthers AG, Newhouse JP, Weiler PC, Hiatt HH. Incidence of adverse events and negligence in hospitalized patients: results of the Harvard Medical Practice Study I. N Engl J Med. 1991;324:370-6.

3. Leape LL, Brennan TA, Laird N, Lawthers AG, Localio AR, Barnes BA, Hebert L, Newhouse JP, Weiler PC, Hiatt HH. The nature of adverse events in hospitalized patients: results of the Harvard Medical Practice Study II. N Engl J Med. 1991;324:377-84.

4. Kohn LT, Corrigan JM, Donaldson MS, editors. To err is human: building a safer health system. Washington, DC: National Academy Press; 2000.

5. Clancy CM. Ten years after to err is human. Am J Med Qual. 2009;24:525-8.

6. Makary MA, Daniel M. Medical error: the third leading cause of death in the US. BMJ. 2016;353:i2139.

7. Davis P. Health care as a risk factor. CMAJ. 2004;170:1688-9.

8. United Nations Department for General Assembly and Conference Management. United Nations regional groups of member states. http://www.un.org/depts/DGACM/RegionalGroups.shtml. Accessed 15 Aug 2015.

9. United Nations. The millennium development goals report, 2015. http://www.un.org/millenniumgoals/2015_MDG_Report/ pdf/MDG\%202015\%20rev\%20(July\%201).pdf. Accessed 15 Aug 2015. 
10. The World Bank. Health expenditure per capita. http://data. worldbank.org/indicator/SH.XPD.PCAP. Accessed 15 Aug 2015.

11. Isah AO, Pal SN, Olsson S, Dodoo A, Bencheikh RS. Specific features of medicines safety and pharmacovigilance in Africa. Ther Adv Drug Saf. 2012;3:25-34.

12. Runciman WB, Roughead EE, Semple SJ, Adams RJ. Adverse drug events and medication errors in Australia. Int J Qual Health Care. 2003;15:49-59.

13. Roughead EE, Semple SJ. Medication safety in acute care in Australia: where are we now? Part 1: a review of the extent and causes of medication problems 2002-2008. Aust New Zealand Health Policy. 2009;6:18.

14. Keers RN, Williams SD, Cooke J, Ashcroft DM. Causes of medication administration errors in hospitals: a systematic review of quantitative and qualitative evidence. Drug Saf. 2013;36:1045-67.

15. Keers RN, Williams SD, Cooke J, Ashcroft DM. Prevalence and nature of medication administration errors in health care settings: a systematic review of direct observational evidence. Ann Pharmacother. 2013;47:237-56.

16. Berdot S, Gillaizeau F, Caruba T, Prognon P, Durieux P, Sabatier B. Drug administration errors in hospital inpatients: a systematic review. PLoS One. 2013;8(6):e68856.

17. Lewis PJ, Dornan T, Taylor D, Tully MP, Wass V, Ashcroft DM. Prevalence, incidence and nature of prescribing errors in hospital inpatients: a systematic review. Drug Saf. 2009;32:379-89.

18. Tully MP, Ashcroft DM, Dornan T, Lewis PJ, Taylor D, Wass $\mathrm{V}$. The causes of and factors associated with prescribing errors in hospital inpatients: a systematic review. Drug Saf. 2009;32:819-36.

19. Brady AM, Malone AM, Fleming S. A literature review of the individual and systems factors that contribute to medication errors in nursing practice. J Nurs Manag. 2009;17:679-97.

20. Alsulami Z, Conroy S, Choonara I. Medication errors in the Middle East countries: a systematic review of the literature. Eur J Clin Pharmacol. 2013;69:995-1008.

21. Mansouri A, Ahmadvand A, Hadjibabaie M, Kargar M, Javadi M, Gholami K. Types and severity of medication errors in Iran; a review of the current literature. Daru. 2013;21:49.

22. Kongkaew C, Noyce PR, Ashcroft DM. Hospital admissions associated with adverse drug reactions: a systematic review of prospective observational studies. Ann Pharmacother. 2008;42:1017-25.

23. Bouvy JC, De Bruin ML, Koopmanschap MA. Epidemiology of adverse drug reactions in Europe: a review of recent observational studies. Drug Saf. 2015;38:437-53.

24. National Coordinating Council for Medication Error Reporting and Prevention (NCCMERP). Defintion and types of medication errors. http://www.nccmerp.org/about-medication-errors. Accessed 30 Jun 2015.

25. Bates DW, Boyle DL, Vander Vliet MB, Schneider J, Leape L. Relationship between medication errors and adverse drug events. J Gen Intern Med. 1995;10:199-205.

26. World Health Organization. International drug monitoring: the role of the hospital. World Health Organ Tech Rep Ser. 1969;425:5-24.

27. David Moher AL, Tetzlaff J, Altman DG, The PRISMA Group. Preferred reporting items for systematic reviews and metaanalyses: the PRISMA statement. PLoS Med. 2009;6(7): e1000097.

28. Smyth RMD, Gargon E, Kirkham J, Cresswell L, Golder S, Smyth R, Williamson P. Adverse drug reactions in children: a systematic review. PLoS One. 2012;7:e24061.
29. Salmasi S, Khan TM, Hong YH, Ming LC, Wong TW. Medication errors in the Southeast Asian countries: a systematic review. PLoS One. 2015;10:e0136545.

30. Aderemi-Williams RI, Awodele O, Boyle CA. Adverse drug reactions amongst adult patients admitted in Lagos State University Teaching Hospital Lagos, Nigeria. Curr Drug Saf. 2015;10:136-44.

31. Benkirane R, Pariente A, Achour S, Ouammi L, Azzouzi A, Soulaymani R. Prevalence and preventability of adverse drug events in a teaching hospital: a cross-sectional study. EMHJ. 2009; $15: 1145-55$.

32. Cooke DI, van der Merwe W, Pudifin DJ. Hospital admissions for adverse reactions to drugs and deliberate self-poisoning. S AfrMed J. 1985;67:770-2.

33. Eshetie TC, Hailemeskel B, Mekonnen N, Paulos G, Mekonnen $\mathrm{AB}$, Girma T. Adverse drug events in hospitalized children at Ethiopian University Hospital: a prospective observational study. BMC Pediatr. 2015;15:83.

34. Kiguba R, Karamagi C, Bird SM. Incidence, risk factors and risk prediction of hospital acquired suspected adverse drug reactions: a prospective cohort of Ugandan inpatients. BMJ Open. 2017;7:e010568. https://doi.org/10.1136/bmjopen-2015-010568.

35. Letaief M, El Mhamdi S, El-Asady R, Siddiqi S, Abdullatif A. Adverse events in a Tunisian hospital: results of a retrospective cohort study. Int J Qual Health Care. 2010;22:380-5.

36. Mabadeje AF, Ilawole CO. Adverse drug reactions in the medical wards of the Lagos University Teaching Hospital: an intensive study. Niger Med J. 1979;9:379-82.

37. Matsaseng T, Moodley J. Adverse events in gynaecology at King Edward VIII Hospital, Durban, South Africa. J Obstet Gynaecol. 2005;25:676-80.

38. Mehta U, Durrheim DN, Blockman M, Kredo T, Gounden R, Barnes KI. Adverse drug reactions in adult medical inpatients in a South African hospital serving a community with a high HIV/ AIDS prevalence: prospective observational study. Br J Clin Pharmacol. 2008;65:396-406.

39. Mouton JP, Mehta U, Parrish AG, Wilson DPK, Stewart A, Njuguna CW, Kramer N, Maartens G, Blockman M, Cohen K. Mortality from adverse drug reactions in adult medical inpatients at four hospitals in South Africa: a cross sectional survey. Br J Clin Pharmacol. 2015;80:818-26.

40. Mouton JP, Njuguna C, Kramer N, Stewart A, Mehta U, Blockman $\mathrm{M}$, et al. Adverse drug reactions causing admission to medical wards: a cross-sectional survey at 4 hospitals in South Africa. Medicine (Baltimore). 2016;95(19):e3437.

41. Oshikoya KA, Njokanma OF, Chukwura HA, Ojo IO. Adverse drug reactions in Nigerian children. Paed Perinat Drug Ther. 2007;8:81-8.

42. Oshikoya KA, Chukwura H, Njokanma OF, Senbanjo IO, Ojo I. Incidence and cost estimate of treating pediatric adverse drug reactions in Lagos, Nigeria. Sao Paulo Med J. 2011;129:153-64.

43. Tipping B, Kalula S, Badri M. The burden and risk factors for adverse drug events in older patients: a prospective cross-sectional study. S Afr Med J. 2006;96:1255-9.

44. Tumwikirize WA, Ogwal-Okeng JW, Vernby A, Anokbonggo WW, Gustafsson LL, Lundborg SC. Adverse drug reactions in patients admitted on internal medicine wards in district and regional hospitals in Uganda. Afr Health Sci. 2011;11:72-8.

45. Agalu A, Ayele Y, Bedada W, Woldie M. Medication prescribing errors in the intensive care unit of Jimma University Specialized Hospital, Southwest Ethiopia. J Multidiscip Healthc. 2011;4:377-82.

46. Ajemigbitse AA, Omole MK, Erhun WO. An assessment of the rate, types and severity of prescribing errors in a tertiary hospital in southwestern Nigeria. Afr J Med Med Sci. 2013;42:339-46. 
47. Ajemigbitse AA, Omole MK, Osi-Ogbu OF, Erhun WO. A qualitative study of causes of prescribing errors among junior medical doctors in a Nigeria in-patient setting. Ann Afr Med. 2013;12:223-31.

48. Ajemigbitse AA, Omole MK, Ezike NC, Erhun WO. Assessment of the knowledge and attitudes of intern doctors to medication prescribing errors in a Nigeria tertiary hospital. J Basic Clin Pharm. 2014;5:7-14.

49. Ajemigbitse AA, Omole MK, Erhun WO. Effect of providing feedback and prescribing education on prescription writing: an intervention study. Ann Afr Med. 2016;15:1-6.

50. Alagha HZ, Badary OA, Ibrahim HM, Sabri NA. Reducing prescribing errors in the paediatric intensive care unit: an experience from Egypt. Acta Paediatrica. 2011;100:169-74.

51. Arulogun OS, Oluwole SK, Titiloye MA. Prescription errors prevalent in four units of a University Teaching Hospital in Nigeria. J Public Health Epidemiol. 2011;3:513-9.

52. Oshikoya KA, Ojo OI. Medication errors in paediatric outpatient prescriptions of a teaching hospital in Nigeria. Nig Q J Hosp Med. 2007;17:74-8.

53. Sada O, Melkie A, Shibeshi W. Medication prescribing errors in the medical intensive care unit of Tikur Anbessa Specialized Hospital, Addis Ababa, Ethiopia. BMC Res Notes. 2015;8:448.

54. Yinusa W. Prescription error in an orthopaedic practice. Niger Postgrad Med J. 2004;11:37-9.

55. Yousif MA, Nizar S, Elmustafa MO, Mustafa MI, Bella MM. Investigation of medication prescribing errors in Wad Medani, Gezira, Sudan. Int J Risk Saf Med. 2011;23:11-6.

56. Zeleke A, Chanie T, Woldie M. Medication prescribing errors and associated factors at the pediatric wards of Dessie Referral Hospital, Northeast Ethiopia. Int Arch Med. 2014;7:18.

57. Acheampong F, Tetteh AR, Anto BP. Medication administration errors in an adult emergency department of a tertiary health care facility in Ghana. J Patient Saf. 2016;12(4):223-8.

58. Agalu A, Ayele Y, Bedada W, Woldie M. Medication administration errors in an intensive care unit in Ethiopia. Int Arch Med. 2012;5:15.

59. al Tehewy M, Fahim H, Gad NI, El Gafary M, Rahman SA. Medication administration errors in a university hospital. J Patient Saf. 2016;12:34-9.

60. Amponsah G, Antwi-Kusi A, Addison W, Abaidoo B. Medication errors among physician-assistants anaesthesia. Adv Anesthesiol. 2016; Article ID 9243587. https://doi.org/10.1155/ 2016/9243587

61. Amucheazi AO, Ajuzieogu OV. A retrospective audit of drug administration errors during elective surgery. Int $\mathrm{J}$ Anesthesiol. 2010; 25. http://ispub.com/IJA/25/1/10065. Accessed 18 Aug 2015.

62. Blignaut AJ, Coetzee SK, Klopper HC, Ellis SM. Medication administration errors and related deviations from safe practice: an observational study. J Clin Nurs. 2017;26(21-22):3610-23.

63. Gordon PC. Wrong drug administration errors amongst anaesthetists in a South African teaching hospital. South Afr J Anaesth Analg. 2004;10:7-8.

64. Gordon PC, Llewellyn RL, James MF. Drug administration errors by South African anaesthetists: a survey. S Afr Med J. 2006;96:630-2.

65. Feleke Y, Girma B. Medication administration errors involving paediatric in-patients in a hospital in Ethiopia. Trop J Pharm Res. 2010;9:401-7.

66. Feleke SA, Mulatu MA, Yesmaw YS. Medication administration error: magnitude and associated factors among nurses in Ethiopia. BMC Nurs. 2015;14:53.

67. Labuschagne M, Robbetze W, Rozmiarek J, Strydom M, Wentzel M, Diedericks BJS, Joubert G. Errors in drug administration by anaesthetists in public hospitals in the Free State. S Afr Med J. 2011;101:324-7.
68. Llewellyn RL, Gordon PC, Wheatcroft D, Lines D, Reed A, Butt $\mathrm{AD}$, Lundgren AC, James MF. Drug administration errors: a prospective survey from three South African teaching hospitals. Anaesth Intensive Care. 2009;37:93-8.

69. Nwasor EO, Sule ST, Mshelia DB. Audit of medication errors by anesthetists in North Western Nigeria. Niger J Clin Pract. 2014;17:226-31.

70. Oshikoya KA, Oreagba IA, Ogunleye OO, Senbanjo IO, MacEbong GL, Olayemi SO. Medication administration errors among paediatric nurses in Lagos public hospitals: an opinion survey. Int J Risk Saf Med. 2013;25:67-78.

71. Agu KA, Oqua D, Adeyanju Z, Isah MA, Adesina A, Ohiaeri SI, Ali PN, Ekechukwu N, Akpakwu AA, Sani T, Omeh IO, King $\mathrm{RC}$, Wutoh $\mathrm{AK}$. The incidence and types of medication errors in patients receiving antiretroviral therapy in resource-constrained settings. PLoS One. 2014;9:e87338.

72. Hawaze S, Negash G, Kebede Y. Medication errors in the adult emergency unit of a tertiary care teaching hospital in Addis Ababa. Arch Pharm Pract. 2013;4:147-53.

73. Kandil M, Sayyed T, Emarh M, Ellakwa H, Masood A. Medication errors in the obstetrics emergency ward in a low resource setting. J Matern Fetal Neonatal Med. 2012;25:1379-82.

74. Ogunleye OO, Oreagba IA, Falade C, Isah A, Enwere O, Olayemi S, et al. Medication errors among health professionals in Nigeria: a national survey. Int $J$ Risk Saf Med. 2016;28(2):77-91.

75. Sabry NA, Abbassi MM. Impact of a clinical pharmacist in the general hospital: an Egyptian trial. Pharmacol Pharm. 2014;5:577-87.

76. Sabry NA, Farid S, Aziz EOA. Role of the pharmacist in identification of medication related problems in the ICU: a preliminary screening study in an Egyptian teaching hospital. Aust J Basic Appl Sci. 2009;3:995-1003.

77. Shehata ZH, Sabri NA, Elmelegy AA. Descriptive analysis of medication errors reported to the Egyptian national online reporting system during six months. J Am Med Inform Assoc. 2016;23:366-74.

78. Benkirane RR, Abouqal R, Haimeur CC, Cherif El Kettani SS, Azzouzi AA, Mdaghri Alaoui AA, Thimou AA, Nejmi MM, Maazouzi WW, Madani NN, R-Edwards I, Soulaymani RR. Incidence of adverse drug events and medication errors in intensive care units: a prospective multicenter study. J Patient Saf. 2009;5:16-22.

79. Dedefo MG, Mitike AH, Angamo MT. Incidence and determinants of medication errors and adverse drug events among hospitalized children in West Ethiopia. BMC Pediatr. 2016;16:81.

80. Jennane N, Madani N, Oulderrkhis R, Abidi K, Khoudri I, Belayachi J, Dendane T, Zeggwagh AA, Abouqal R. Incidence of medication errors in a Moroccan medical intensive care unit. Int Arch Med. 2011;4:32.

81. Begaud B, Evreux JC, Jouglard J, Lagier G. Imputation of the unexpected or toxic effects of drugs: actualization of the method used in France. Thérapie. 1985;40:111-8.

82. WHO Collaborating Center for International Drug Monitoring (UMC). Safety monitoring of medicinal products: guidelines for setting up and running a pharmacovigilance center. London: EQUUS; 2000. http://apps.who.int/medicinedocs/en/d/Jh2934e/. Accessed 10 Oct 2016.

83. Schumock GT, Thornton JP. Focusing on the preventability of adverse drug reactions. Hosp Pharm. 1992;27:538.

84. Trunet P, Le Gall JR, Lhoste F, Regnier B, Saillard Y, Carlet J, Rapin M. The role of iatrogenic disease in admissions to intensive care. JAMA. 1980;244:2617-20.

85. World Health Organization. The use of the WHO-UMC system for standardized case causality assessment. Uppsala: Uppsala 
Monitoring Center. http://who-umc.org/Graphics/24734.pdf. Accessed 10 Oct 2016.

86. Naranjo CA, Busto U, Sellers EM, Sandor P, Ruiz I, Roberts EA, Janecek E, Domecq C, Greenblatt DJ. A method for estimating the probability of adverse drug reactions. Clin Pharmacol Ther. 1981;30:239-45.

87. US Department of Health and Human Services, National Institutes of Health, National Institute of Allergy and Infectious Diseases. Division of AIDS (DAIDS) Table for Grading the Severity of Adult and Paediatric Adverse Events. 2004 clarification dated August 2009; Version 1.0, December 2004. http:// rsc.tech-res.com/safetyandpharmacovigilance/gradingtables.aspx. Accessed 11 Nov 2017

88. Wilson RM, Runciman WB, Gibberd RW, Harrison BT, Newby L, Hamilton JD. The quality in Australian health care study. Med J Aust. 1995;163:458-76.

89. Edwards IR, Biriell C. Harmonization in pharmacovigilance. Drug Saf. 1994;10:93-102.

90. Temple ME, Robinson RF, Miller JC, Hayes JR, Nahata MC. Frequency and preventability of adverse drug reactions in paediatric patients. Drug Saf. 2004;27:819-29.

91. Jones JK. Adverse drug reactions in the community health setting: approaches to recognizing, counseling, and reporting. Fam Community Health. 1982;5:58-67.

92. Martínez-Mir I, García-López M, Palop V, Ferrer JM, Estañ L, Rubio E, Morales-Olivas FJ. A prospective study of adverse drug reactions as a cause of admission to a paediatric hospital. Br J Clin Pharmacol. 1996;42(3):319-24.

93. Schirm E, Tobi H, van Pulenbroek EP, Monster-Simons MH, de Jongvan den Berg LT. Reported adverse drug reactions and their determinants in Dutch children outside the hospital. Pharmacoepidemiol Drug Saf. 2004;13:159-65.

94. Nebeker JR, Barach P, Samore MH. Clarifying adverse drug events: a clinician's guide to terminology, documentation, and reporting. Ann Intern Med. 2004;140:795-801.

95. Dormann H, Muth-Selbach U, Krebs S, Criegee-Rieck M, Tegeder I, Schneider HT, Hahn EG, Levy M, Brune K, Geisslinger G. Incidence and costs of adverse drug reactions during hospitalisation: computerised monitoring versus stimulated spontaneous reporting. Drug Saf. 2000;22:161-8.

96. Dornan T, Ashcroft D, Heathfield H, Lewis P, Miles J, Taylor D, Tully M, Wass V. An in-depth investigation into causes of prescribing errors by foundation trainees in relation to their medical education: EQUIP study. A report to the General Medical Council, 2009. http://www.gmc-uk.org/FINAL_ Report_prevalence_and_causes-of_prescribing_errors.pdf28935150.pdf. Accessed 10 Oct 2016.

97. Neville R, Roberts F, Livingstone S, Crombie I. A classification of prescription errors. JRCGP. 1989;39:110-2.

98. Chua SS, Chua HM, Omar A. Drug administration errors in paediatric wards: a direct observation approach. Eur J Pediatr. 2010;169:603-11.

99. Webster CS, Merry AF, Larsson L, McGrath KA, Weller J. The frequency and nature of drug administration error during anaesthesia. Anaesth Intensive Care. 2001;29:494-500.
100. Wheeler SJ, Wheeler DW. Medication errors in anaesthesia and critical care. Anaesthesia. 2005;60:257-73.

101. Juntti-Patinen L, Neuvonen PJ. Drug-related deaths in a university central hospital. Eur J Clin Pharmacol. 2002;58:479-82.

102. Davies EC, Green CF, Taylor S, Williamson PR, Mottram DR, Pirmohamed M. Adverse drug reactions in hospital in-patients: a prospective analysis of 3695 patient-episodes. PLoS One. 2009;4:e4439.

103. Alhawassi TM, Krass I, Bajorek BV, Pont LG. A systematic review of the prevalence and risk factors for adverse drug reactions in the elderly in the acute care setting. Clin Interv Aging. 2014;9:2079-86.

104. Hakkarainen KM, Hedna K, Petzold M, Hägg S. Percentage of patients with preventable adverse drug reactions and preventability of adverse drug reactions: a meta-analysis. PLoS One. 2012;7:e33236.

105. Leendertse AJ, Visser D, Egberts AC, van den Bemt PMLA. The relationship between study characteristics and the prevalence of medication-related hospitalizations. Drug Saf. 2010;33:233-44.

106. Agbabiaka T, Savović J, Ernst E. Methods for causality assessment of adverse drug reactions. Drug Saf. 2008;31:21-37.

107. Hakkarainen KM, Andersson Sundell K, Petzold M, Hagg S. Methods for assessing the preventability of adverse drug events: a systematic review. Drug Saf. 2012;35:105-26.

108. Dean Franklin B, Vincent C, Schachter M, Barber N. The incidence of prescribing errors in hospital inpatients: an overview of the research methods. Drug Saf. 2005;28:891-900.

109. Garfield S, Reynolds M, Dermont L, Franklin BD. Measuring the severity of prescribing errors: a systematic review. Drug Saf. 2013;36:1151-7.

110. Radley DC, Wasserman MR, Olsho LE, Shoemaker SJ, Spranca $\mathrm{MD}$, Bradshaw B. Reduction in medication errors in hospitals due to adoption of computerized provider order entry systems. J Am Med Inform Assoc. 2013;20:470-6.

111. Costello JL, Torowicz DL, Yeh TS. Effects of a pharmacist-led pediatrics medication safety team on medication-error reporting. Am J Health Syst Pharm. 2007;64:1422-6.

112. Mekonnen AB, McLachlan AJ, Brien JE. Effectiveness of pharmacist-led medication reconciliation programmes on clinical outcomes at hospital transitions: a systematic review and meta-analysis. BMJ Open. 2016;6:e010003.

113. Mekonnen AB, McLachlan AJ, Brien JE. Pharmacy-led medication reconciliation programmes at hospital transitions: a systematic review and meta-analysis. J Clin Pharm Ther. 2016;41:128-44.

114. Tierney WM, Achieng M, Baker E, Bell A, Biondich P, Braitstein $\mathrm{P}$, et al. Experience implementing electronic health records in three East African countries. Stud Health Technol Inform. 2010;160:371-5.

115. Mekonnen AB, Yesuf EA, Odegard PS, Wega SS. Implementing ward based clinical pharmacy services in an Ethiopian University Hospital. Pharm Pract. 2013;11:51-7. 